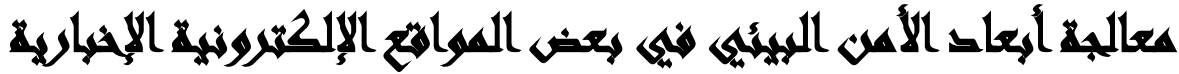

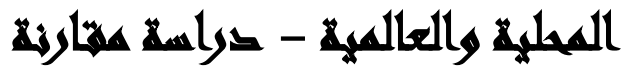

$[1 \mathrm{~V}]$

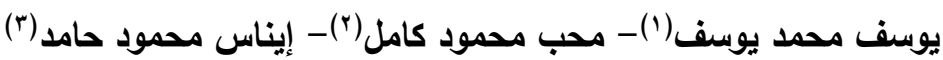

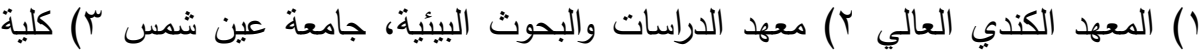
الدراسات العليا للطفولة، جامعة عين شمس العرال

\section{المستخله}

تهدف الدراسة إلى التعرف على طبيعة معالجة المواقع الإلكترونية الإخبارية عينة

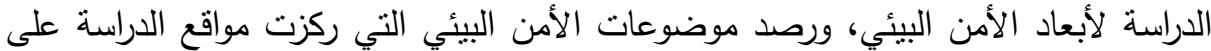

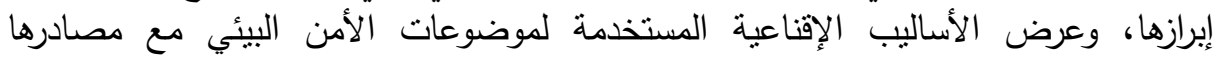

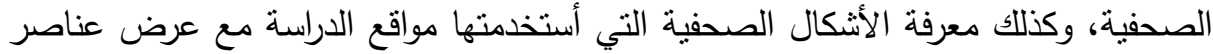
الإبراز والتدعيم والخدمات التفاعلية التي صاحبت المواد الخبرية والوقوف على التى أوجه التها الأتفاق

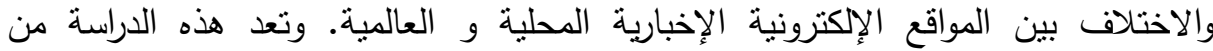

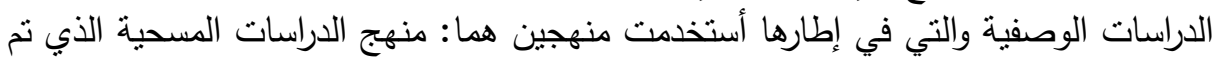

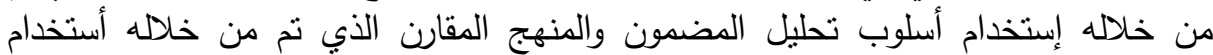

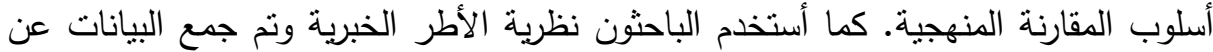

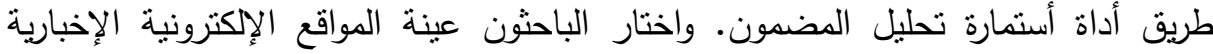

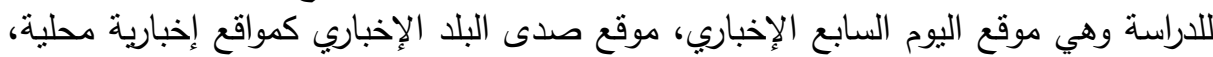

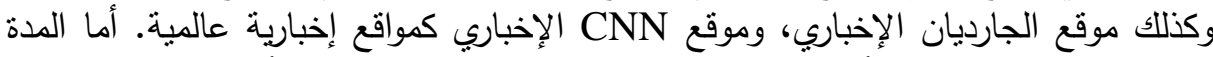

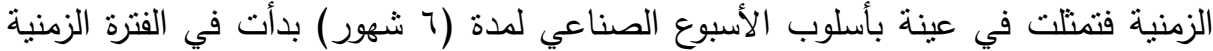

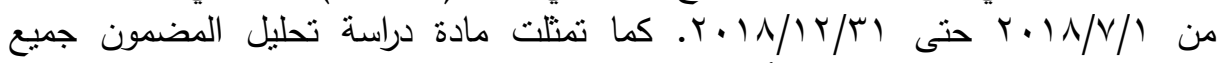
الموضوعات التي تخص ابعاد الأمن البيئي المختلفة في الماني المواقع الإلكترونية الإخبارية عينة

وتوصلت نتائج الدراسة إلى وجود فروق ذات دلالة إحصائية بين المواقع الإلكترونية

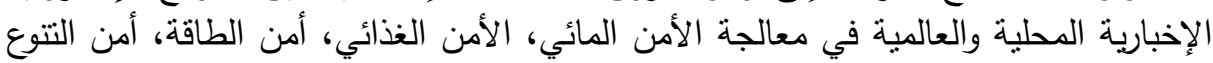

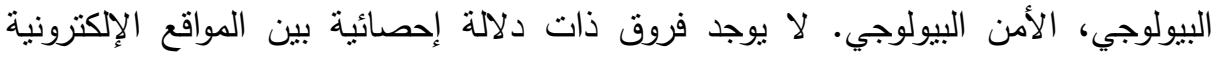
الإخبارية المحلية والعالمية في معالجة الأمن النووي، الأمن المناخي. 
Sلمات مفتاحية: الأمن البيئي Newsironmental Security المعالجة الإخبارية News News Websites المواقع الإكترونية الإخبارية Treatment

\section{xaradl}

يواجه العالم اليوم تحديات متعاظمة، تهدد أمن الانسان نتيجة الضغوط البيئية، وقد

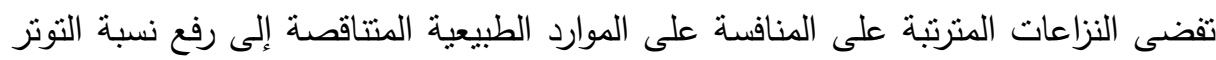
في العلاقات بين الجماعات والسكان والدول، فمن أهم الأسباب لتدهور حقوق الانسان والأنية الأمن

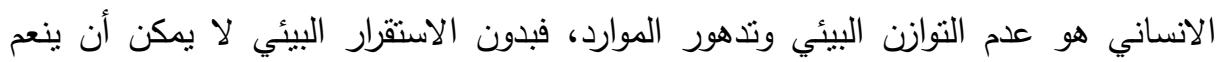

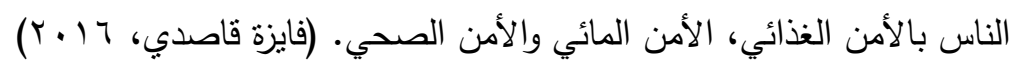

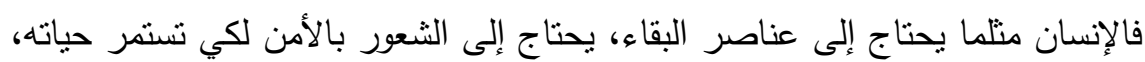

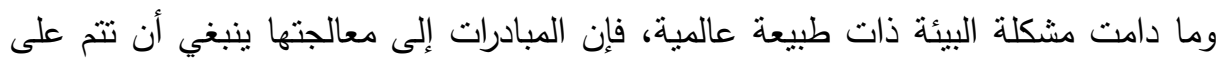

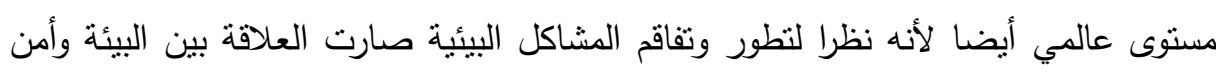

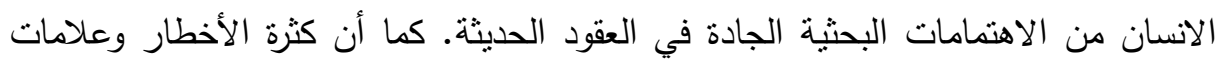
التذهور البيئي أحدثت تحولا كبيرا في مفهوم الأمن الذي كان من صميم اللوازم العسكرية والسياسية فأصبح في سياق التحول الحديث ذات صلة بالمسائل البيئية والأقتصادية والاجتماعية.

وعليه فإن ظهور الأمن البيئي كقضية جوهرية تأخذ أهمية قصوى في ظل ما تعانيه البيئة ومواردها من تدهور وما يعتريها من خراب و دمار يهدد حياة الكائنات الحية البشرية،

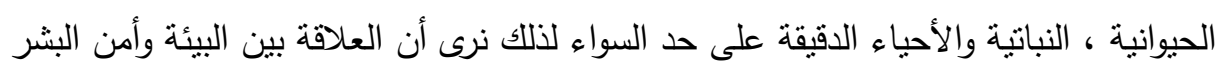
والطبيعة محور اهتمام الكثير من الأبحاث وموضوع العديد من المنشورات في العقود الأخيرة، بل أصبحت مؤخرا محورا مهما من السياسة البيئية الدولية.

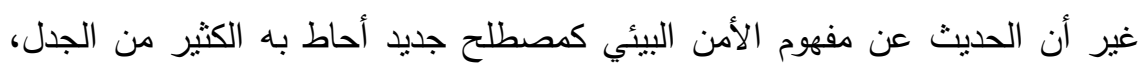

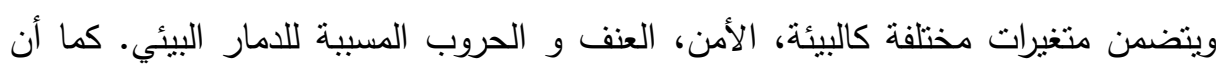

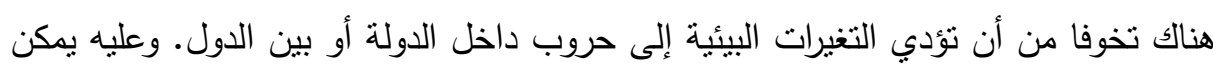

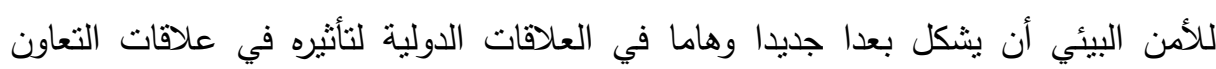


والصراع بين الدول وعمله على تعبئة الجماهير وراء أهداف حمائية. ومن هنا تبرز معان منتوعة تمنل مفهوم الأمن البيئي.

فبحسب دراسة Gleditsch (2001) فإن الأمن البيئي يعني توفر الخدمات البيئية

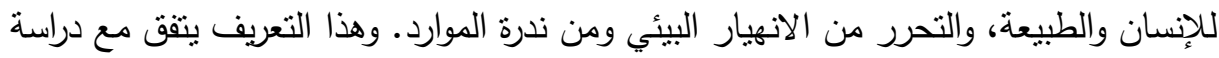
Colonel ونوعية توفر خدمات ومنتجات للإنسان لإستمرار حياته ورفاهيته.

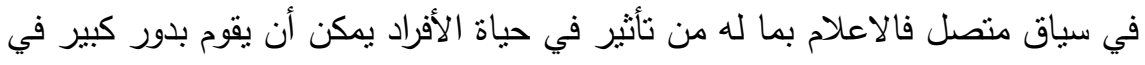
تعريف الأفراد بقضايا الأمن البيئي بصفة مستمرة وفي تعديل اتجاتهم وتغيير سلوكهم عن

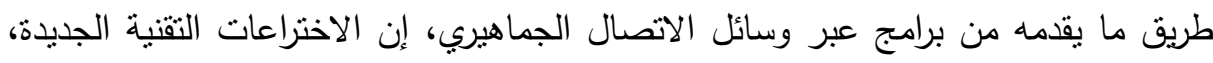

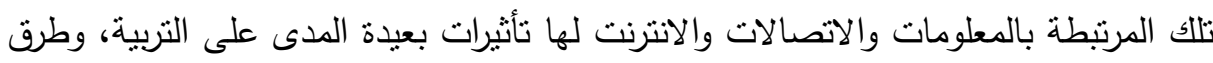

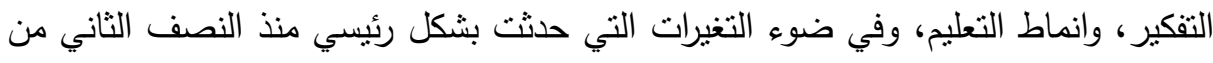

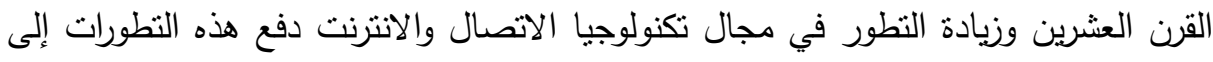

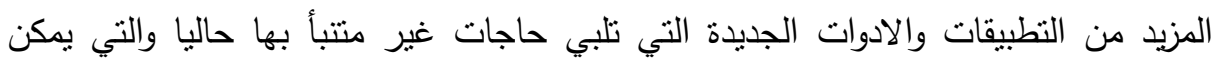
استخدامها لتحقيق أهداف التربية البيئية، تتمية المفاهيم البيئية والوعي البيئي لادى أفراد

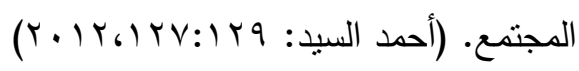
ويعتبر الانترنت وسيلة الاتصال الأسرع نموا في التاريخ ذلك أنها أصبحت عاملا أساسيا

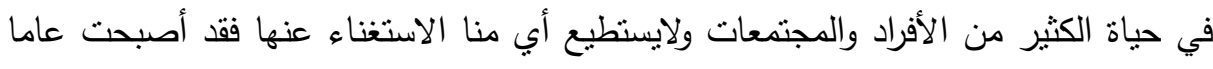

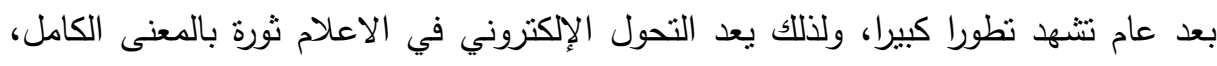

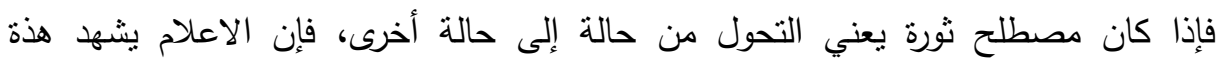
الوضعية بالضبط في الوقت الحاضر، حيث بدأ تتحول من منتج مطبوع إلى منتج يتم استقباله على شاشة. بناء عليه ظهر شكل اعلامي جديد يقدم الأخبار والمعلومات ونتابع عليه الأحداث

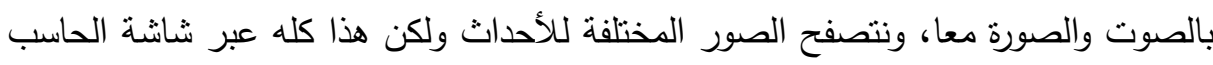

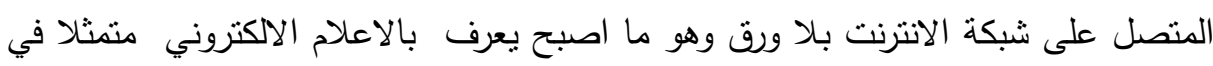


المواقع الاككترونية الاخبارية. إن وسائل الاعلام المختلفة بشكلها السمعي، البصري و المقرؤ

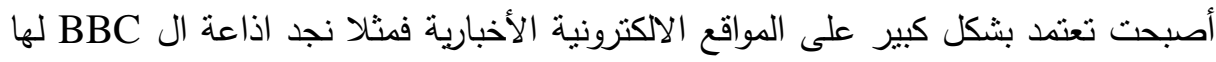

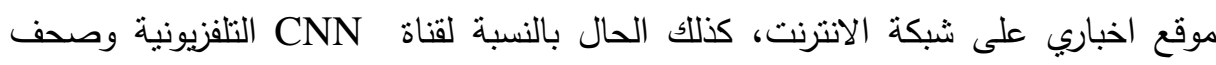
ورقية مثل الواشنطن بوست وغيرهم من وسائل الاعلام المحلية، الاقليمية و العالمية.

\section{مش212}

نالت قضايا البيئة نصيبا من التناول والعرض في وسائل الاعلام التقليدي والالكتروني،

على المستوى العالمي والاقليمي والمحلي، كما استحوذت بعض القضايا البيئية على اهتمام بعض المواقع الاخبارية. ولما كانت أبعاد الأمن البيئي من أكثر القضايا البيئية التي تمثل جزءا من الصراعات

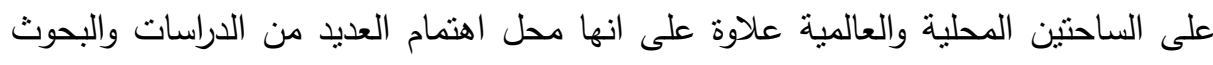

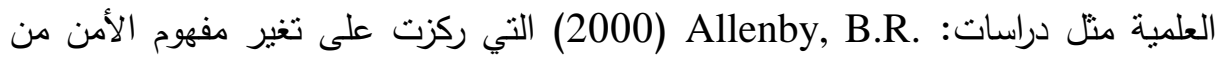
الأمن التقليدي إلى الأمن الغير تقليدي أو الأمن الثامل الذي يتضمن الأمن البيئي. كذللك

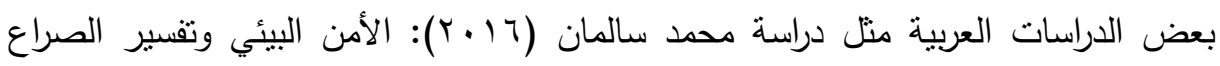

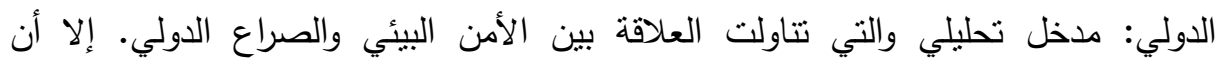
الباحثون لم يرصد أي من الدراسات الإعلامية التي قامت بالمعالجة الإلئ الإخبارية لأبعاد الأمن البيئي لذا فإننا في هذه الدراسة بصدد رصد وتحليل المعالجة الاعلامية لأبعاد الأمن البيئي

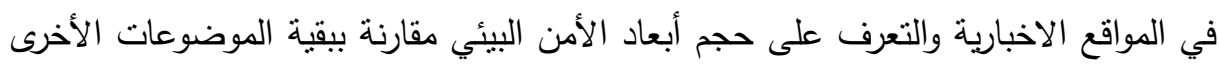

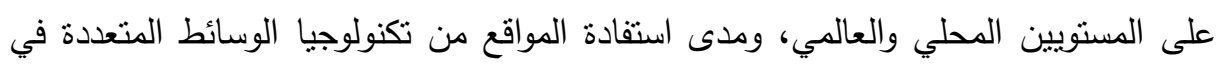

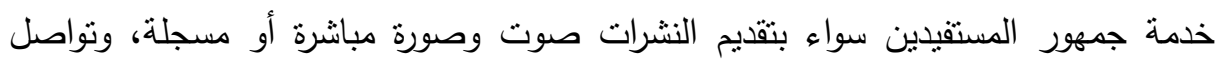

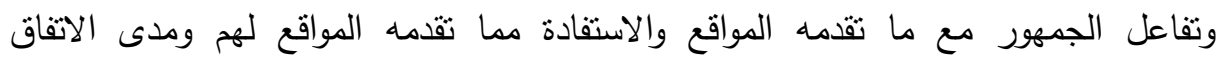
والاختلاف في طبيعة المعالجة وتغطية الأحداث والقضايا ذات الصلة بأبعاد الأمن البيئي.

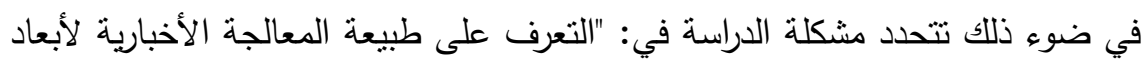
الأمن البيئي في بعض المواقع الالكترونية الاخبارية محلياً وعالمياً. 


\section{أسئلا السواسمة}

السؤال الرئيسي: "ما مدى معالجة أبعاد الأمن البيئي في المواقع الاككترونية الاخبارية

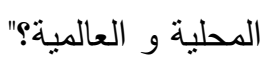

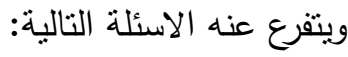

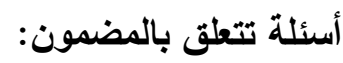

• ما أبعاد الأمن البيئي التي ينبغي تضمينها في المواقع الالكترونية الإخبارية؟ • ما مضمون (موضوعات) الأمن البيئي في المواقع الإلكترونية الإخبارية؟

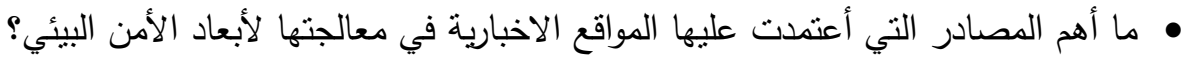

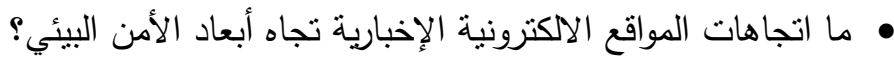
• ما القوى الفاعلة وأدوارها في مضامين التحقيقات الإخبارية لأبعاد الأمن البيئي؟

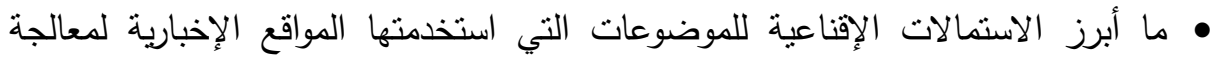

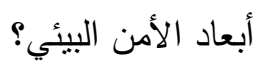
• • ما الأطر الخبرية التي استخدمت في المعالجة الخبرية؟

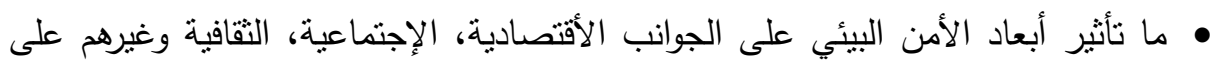

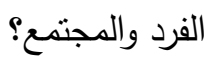

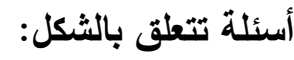
• ما الأشكال الصحفية التي استخدمتها مواقع عينة الدراسة في معالجتها لأبعاد الأمن البيئي! • ما عناصر التدعيم، الوسائط المتعددة، الإبراز والخدمات التفاعلية التي صاحبت المواد

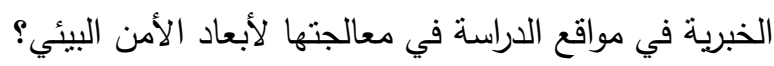




\section{أهساهن الصوراسها}

• معرفة أولويات اهتمامات المواقع الاككترونية الاخبارية ومساحة المواد الاعلامية التي

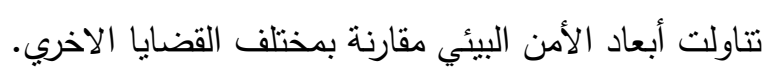

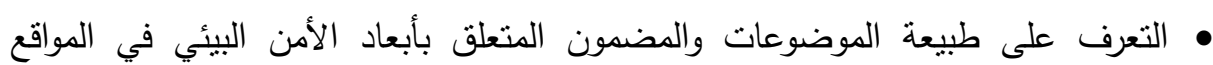
الالكترونية الأخبارية المحلية والعالمية من حيث المظاهر والأسباب والآثار المترتبة عليها.

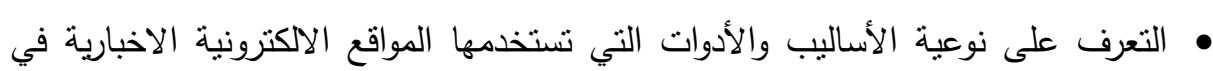
عرض الموضوعات المتعلقة بأبعاد الأمن البيئي. • تحديد مكانة الموضوعات الخاصة بأبعاد الأمن البيئي.

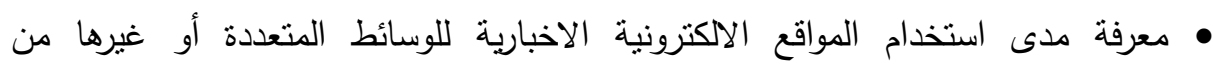
الامكانيات المتوفرة لديها للموضوعات المتعلقة بأبعاد الأمن البيئي.

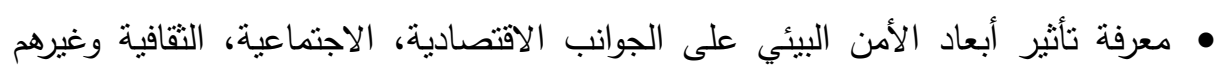

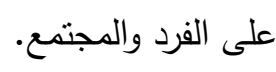

\section{هروض السواسم}

•• الفرض الأول: توجد فروق ذات دلالة إحصائية بين المواقع الإلكترونية الإخبارية المحلية

$$
\text { والعالمية في معالجة الأمن المائي. }
$$

•ـ الفرض الثاني: توجد فروق ذات دلالة إحصائية بين المواقع الإلكترونية الإخبارية المحلية

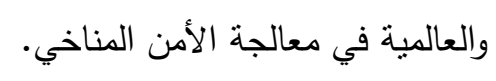

•• الفرض الثالث: توجد فروق ذات دلالة إحصائية بين المواقع الإلكترونية الإخبارية المحلية

$$
\text { والعالمية في معالجة الأمن الغذائي. }
$$

•ـ الفرض الرابع: نوجد فروق ذات دلالة إحصائية بين المواقع الإككترونية الإخبارية المحلية

$$
\text { والعالمية في معالجة الأمن النووي. }
$$

•ـ الفرض الخامس: توجد فروق ذات دلالة إحصائية بين المواقع الإلكترونية الإخبارية المحلية والعالمية في معالجة الأمن البيولوجي. 
•ـ الفرض السادس: توجد فروق ذات دلالة إحصائية بين المواقع الإلكترونية الإخبارية المحلية والعالمية في معالجة أمن الطاقة.

•• الفرض السابع: توجد فروق ذات دلالة إحصائية بين المواقع الإلكترونية الإخبارية المحلية والعالمية في معالجة أمن التتوع البيولوجي.

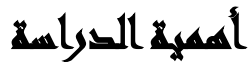

تتبع أهمية البحث من الدور الذي تقوم به وسائل الاعلام على الساحة المحلية والعالمية باعتبارها مرآة للواقع الحالي وما ينطوي عليه من أحداث و صن صراعات فهي تعمل على اضفاء الثرعية أو القبول الاجتماعي على أفكار ومفاهيم معينة واستبعاد أفكار ومفاهيم أخرى.

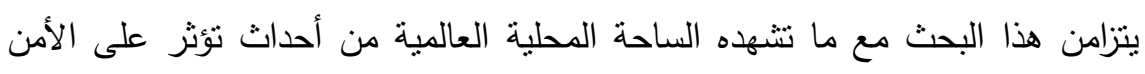

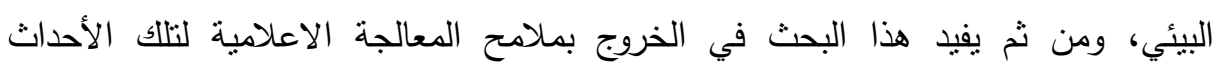
باعتبارها أحداث مؤثرة في المجتمع المحلي والعالمي.

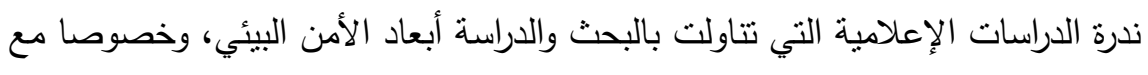

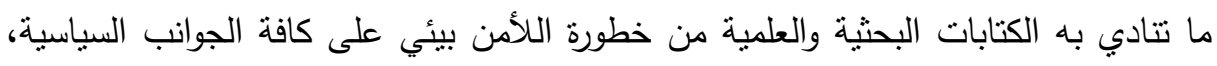

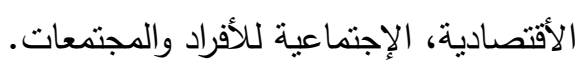
الدور المتزايد الذي تقوم به المواقع الإلكترونية الإخبارية في معالجة الأحداث والقضايا بشكل عام وأحداث الأمن البيئي بشكل خاص، وبالتالي يزداد إعتماد الجمهور على وسائل الإنل

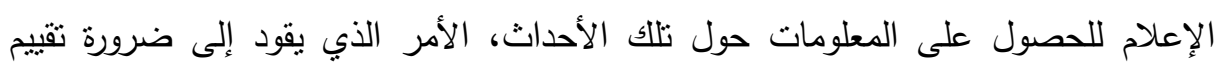

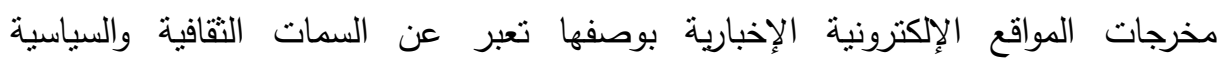
والأيديولوجية التي تعمل وسائل الإعلام في إطارها. مجتمع الاراسة وعينتها: يتضمن مجتمع الدراسة المواقع الإلكترونية الإخبارية التي تتسم بالدورية والانتظام. 
عينة الاراسة: تتضمن العينة أربع مواقع إلكترونية إخبارية هي: اليوم السابع، صدى البلد، الجارديان، CNN

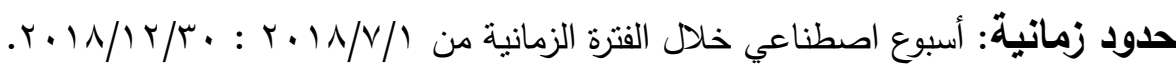

\section{منهمج القراسمة}

المنهج المسحي: هو أكثر المناهج العلمية ملائمة للبحوث الوصفية لكونه جهاً علمياً منظماً يساعد في الحصول على المعلومات والخصائص التي تتعلق بالظاهرة موضع الدراسة. ويستخدم الباحثون هذا المنهج لوصف سمات معالجة المواقع الإلكترونية الإخبارية عينة الاراسة لأبعاد الأمن البيئي. المنهج المقارن: لمقارنة النتائج التي توصلت إليها الدراسة الميدانية في المواقع الاكترونية الاخبارية لرصد درجة الاهتمام التي نوليها كل موقع بأبعاد الامن البيئي وأبعاد المعالجة الاعلامية. - الايه

\section{أسوائش الفواسمة}

استمارة تحليل المحتوى: هي أداة لتحليل مضمون أبعاد الأمن البيئي في المواقع الإخبارية عينة الدراسة والإجابة عن تساؤلاتها، وهي تتمثل في مجموعة من الخطوات المنهجية التي تسعى إلى إكتثاف المعاني في المحتوى من خلال البحث الموضوعي والمنظم لسمات الظاهرة.

\section{همطللحاهي الصواسما}

المعالجة الإخبارية: الطريقة التي تتتاول من خلالها المواقع الإلكترونية الإخبارية (عينة الدراسة) أبعاد الأمن البيئي، ولهذة المعالجة شقان أولهما خاص بالهضئهون ومن خلاله تقوم المواقع الإكترونية عينة الدراسة بتوظيف مجموعة من الأطر الخبرية، والثق الثاني هو الثكل والأسلوب المستخدم في عرض وتقديم تلك الأحداث والمساحة التي خصصنتها المواقع الاطع 
الإلكترونية عينة الدراسة أو الزمن الذي خصصته لعرض تلاك الأحداث إلى جانب وسائل

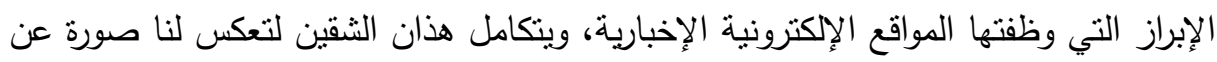

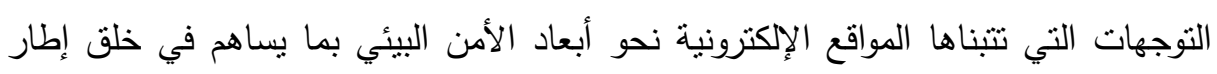
عام يتماشي بدوره مع سياسات المواقع الإخبارية.

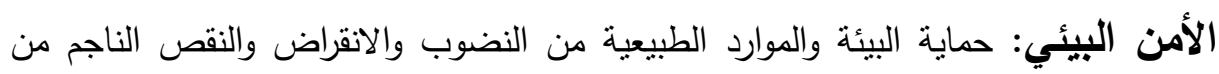
المخاطر والملوثات والجرائم المتعدة التي نرتكب في حق تتنمية المصادر والموارد الطبيعية والاخلال بالتوازن البيئي. المواقع الالكترونية الإخبارية: يقصد به أحد أنكال الاعلام الالكتروني ذات عنوان ثابت

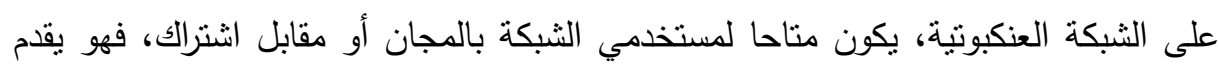

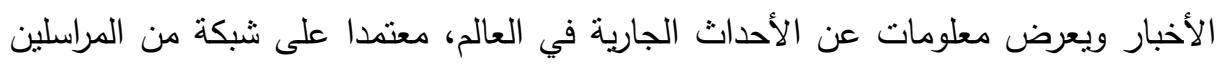

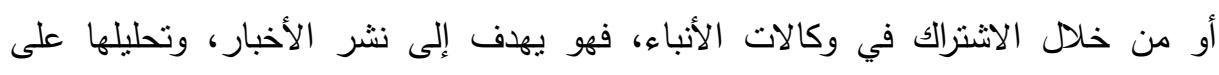
صفحات الموقع وبشكل دوري، بالإضافة إلى تقديم موضوعات أخرى: اقتصادية، اجتماعية، رياضية، ثقافية، فنية.

\section{إجزاعاهي التواسمة}

للإجابة على أسئلة الدراسة والتحقق من صحة الفروض، قام الباحثون بالإجراءات التالية: أولاً: إعداد قائمة بأبعاد الأمن البيئي. حيث أتبع الباحثون الخطوات الآتية :

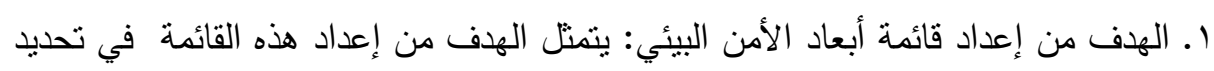

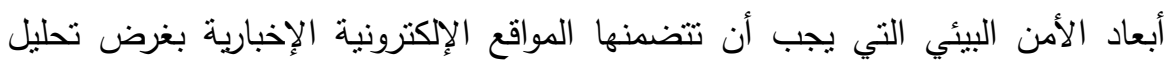
مضمونها. r. مصادر اشتقاق قائمة أبعاد الأمن البيئي: استعان الباحثون ببعض البحوث الأجنبية المرتبطة بدراسة أبعاد الأمن البيئي في إعداد هذة القائمة مثل دراسات: Simon Dalby 2013; Da Nang, Vietnam 2018; Hans Brauch2011

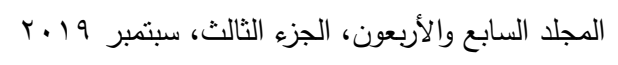


r. إعداد الصورة الأولية لقائمة أبعاد الأمن البيئي: أعدت قائمة مبدئية لأبعاد الأمن البيئي

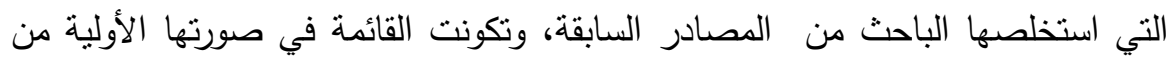
(T) أبعاد هي: الأمن المائي، الأمن الغذائي، الأمن النووي (الإشعاعي)، الأمن الأن

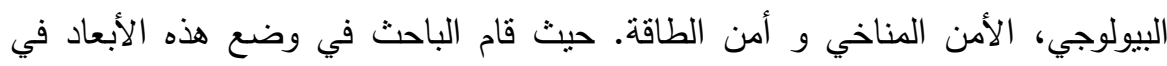

$$
\text { قائمة مبدئية. }
$$

ع. إجراءات ضبط قائمة أبعاد الأمن البيئي: اتبع الباحثون الإجراءات التالية للتحقق من ضبط

القائمة:

أ. تحديد صدق القائمة: نم تضمين القائمة في استطلاع رأي ثم توجيهها لمجموعة من

المحكمين المتخصصين بهدف تحديد صدق القائمة حيث طلب منهم تحديد: مدى صحة

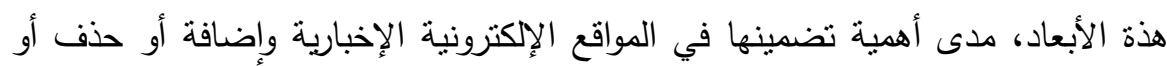

$$
\text { تعديل ما يرونه مناسبًا. }
$$

وقد اعتمد الباحث على صدق المحكمين في التحقق من صدق قائمة أبعاد الأمن

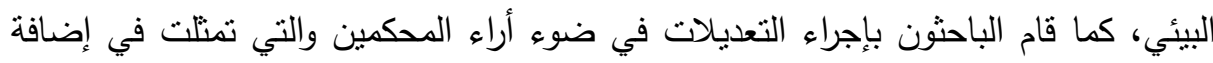

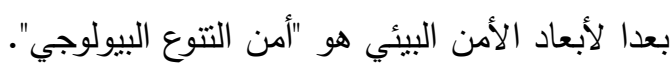
ب.ثبات قائمة أبعاد الأمن البيئي: تم حساب لثادئ لثات القائمة بحساب نسبة الاتفاق بين المحكمين باستخدام معادلة كوبر Copper. وحيث إن مستوى التبات في معادلة كوبر

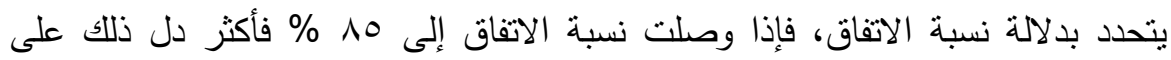

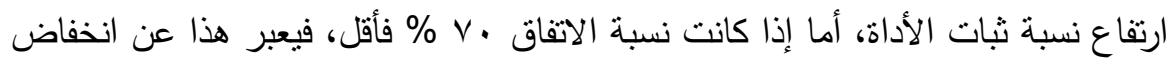

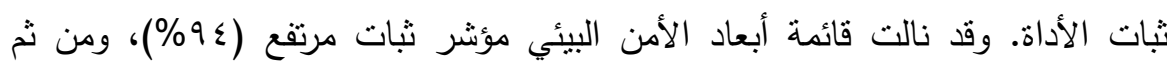
أصبحت القائمة في صورتها النهائية. 0. الصورة النهائية لقائمة أبعاد البيئي: بعد إجراء التعديلات المناسبة التي أثنار إليها السادة

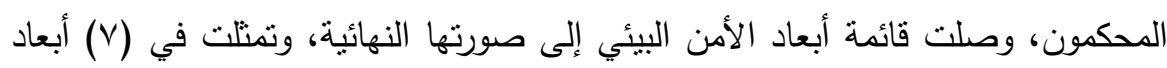

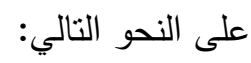


الأمن المائي: قدرة السكان على ضمان الوصول المستدام إلى كميات كافية من المياه ذات النوعية المقبولة للحفاظ على سبل العيش ورفاهية الإنسان والتتمية الاجتماعية والاقتصادية، لضمان الحماية من التلوث الذي تتقله المياه والكوارث المرتبطة بالمياه، وللحفاظ على النظم الإيكولوجية في مناخ من السلام والاستقرار السياسي. (طبقا لتعريف هيئة الأمم المتحدة) الأمن الغذائي: تمكن الناس في جميع الأوقات اجتماعيا واقتصاديا من الحصول على العى

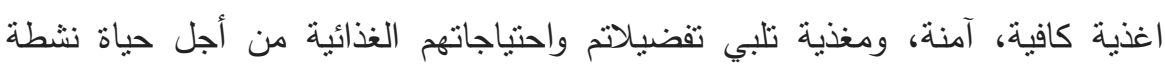

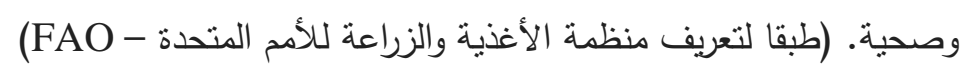
الأمن المناخي: اتخاذ إجراءات عاجلة لمكافحة تغير المناخ وآثاره. الأمن النووي (الاشعاعي): اتخاذ كل الإجراءات الممكنة لـنع وقوع الحوادث النووية والأثعاعية بما بعني حماية الناس والممتلكات والمجتمع والبيئة من الآثار الضارة للإثعاع. (طبقا لتعريف الوكالة الدولية للطاقة الذرية)

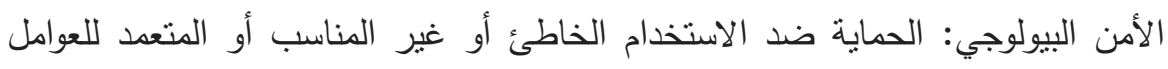
البيولوجية أو التكنولوجيا الحيوية التي يحتمل أن تكون خطرة، بما في ذلك تطوير الأسلحة البيولوجية أو إنتاجها أو تخزينها أو استخدامها وكذلك تفشي الأمراض النانئئة النئة والوبائية.

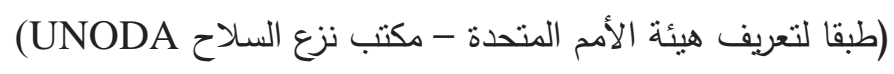

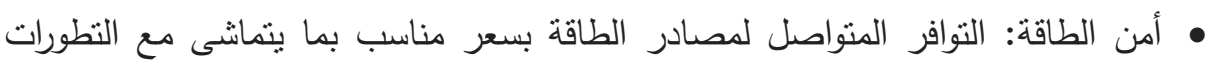

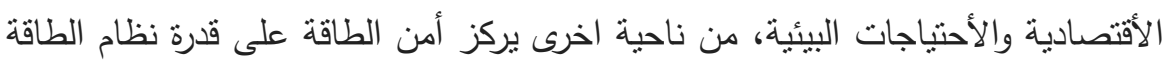

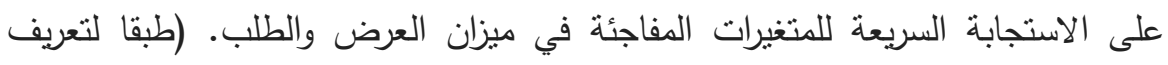
الوكالة الدولية للطاقة الذربة) • أمن التتوع البيولوجي: التتوع الموجود في الكائنات الحبة والذي بتراوح بين التركيب الجيني للنباتات والحيوانات وبين التتوع الثقافي. (طبقا لتعريف منظمة الصحة العالمية) 
ثانياً: إعداد استمارة تحليل المضمون:

() الهدف من إعداد استمارة تحليل المضمون: يتمثل الهدف من إعداد هذه الأستمارة في

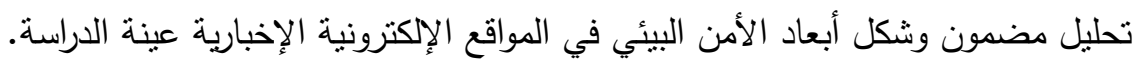

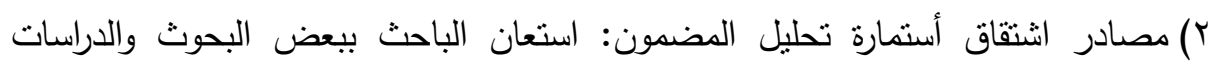

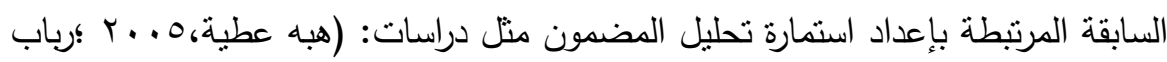

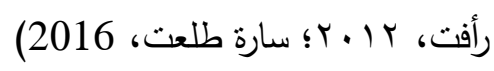

r) إعداد الصورة الأولية لأستمارة تحليل المضمون:أعدت استمارة مبدئية لتحليل مضمون

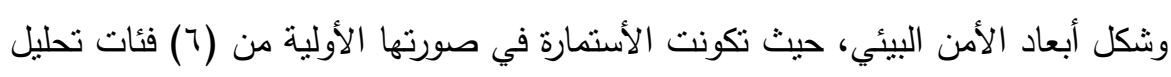

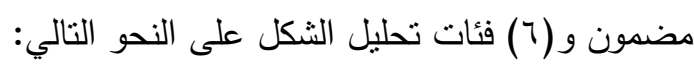

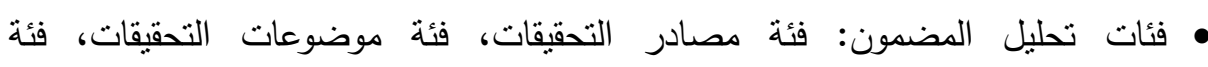

الاتجاهات، فئة القوى الفاعلة، فئة الأستمالات الإقناعية، فئة الأطر الخبرية.

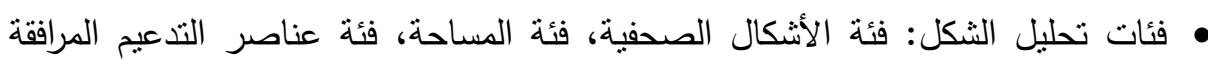
للمادة الخبرية، فئة عناصر الإبراز المرافقة للمادة الخبرية، فئة عناصر الخدمات التفاعلية المرافقة للمادة الخبرية، فئة نوع التغطية.

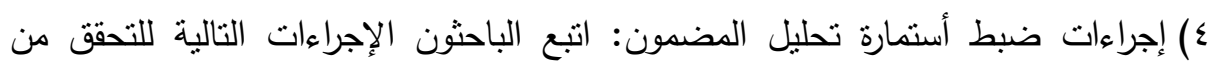
ضبط الأستمارة: • تحديد صدق الأستمارة: نم تضمين الأستمارة في استطلاع رأي ثم نوجيهها لمجموعة من

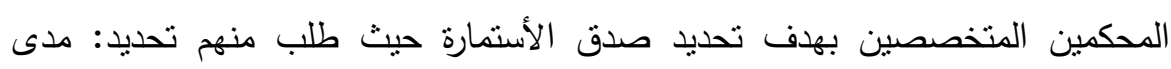

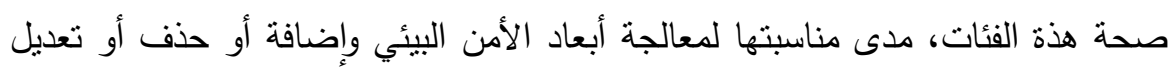
ما يرونه مناسبًا.

وقد اعتمد الباحثون على صدق المحكمين في التحقق من صدق استمارة تحليل المضمون،

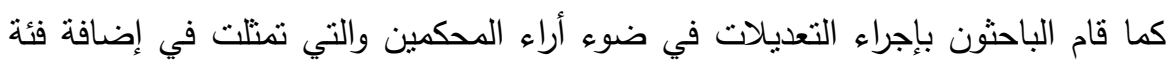

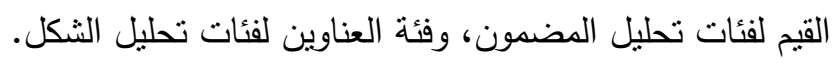


ثبات استمارة تحليل المضمون: الثبات بإعادة التطبيق: أجرى الباحثون تحليل محتوى باستخدام استمارة تحليل المحتوى التى أعدها الباحثون وتم إحصاء عدد التكرارات لكل نل

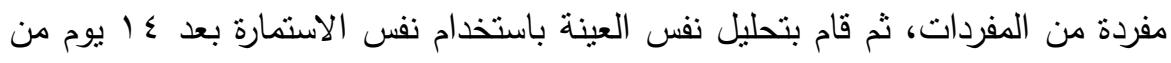

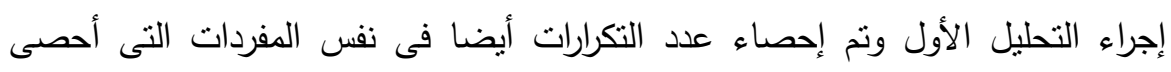
تكرارها فى المرة الأولى. 0) الصورة النهائية لأستمارة تحليل المضمون: بعد إجراء التعديلات المناسبة التي أثنار إليها

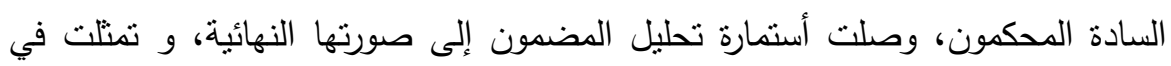

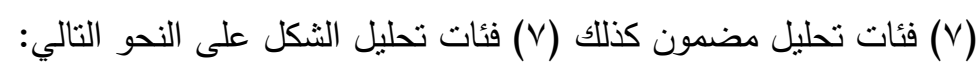
فئات المضمون (ماذا قيل):

فئة مصادر التحقيقات: ويقصد بها مصادر موضوعات الأمن البيئي في المواقع الإلكترونية الإخبارية "عينة الدراسة" مثل مصدر المندبون والمراسلون، وكالات الأنباء

$$
\text { العربية، وكالات الأنباء العالمية. }
$$

هئة موضوعات التحقيقات: يقصد بها الفئة التي تهدف إلى الوقوف على الموضوعات التي كانت تتشرها مواقع الدراسة أثثاء معالجتها لأبعاد الأمن البيئي.

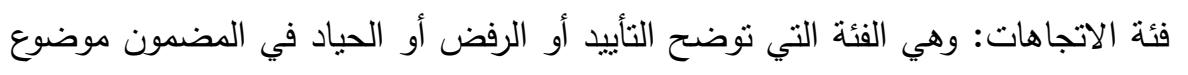
التحليل بالنسبة للمواقف أو القضايا أو الموضوعات المتضيحة التضنة التبنة فيه (أبعاد الأمن البيئي المتضمنة في المواقع الإلكترونية الإخبارية عينة الدراسة). • فئة القوى الفاعلة: والمقصود بها الثخصيات البارزة ذات التأثير في مجريات الأحداث المرتبطة بأبعاد الأمن البيئي. فئة الأستمالات الإقناعية: يقصد بها الاساليب الاقناعية التي استخدمتها المواقع الاخبارية

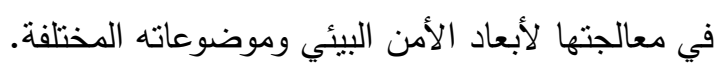

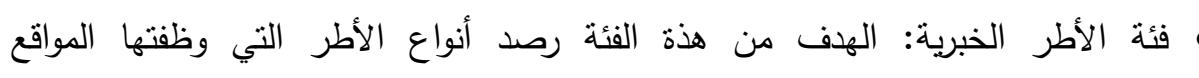

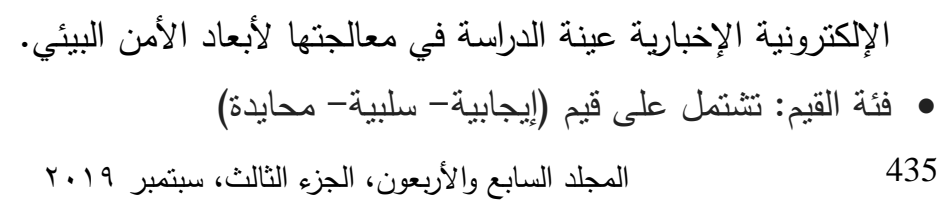


فئات الثكل (كيف قيل): الفئات التي تتعلق بوصف الثكل الذي قدمت من خلاله المادة الخبرية التي سيتم تحليلها للوقوف على دلالالتها المتصلة بأهداف الدراسة وقسمت بلى بلى بلى • فئة الأشكال الصحفية: تختص هذه الفئة بالأشكال الصحفية التي قدمت من خلالها لالها المادة

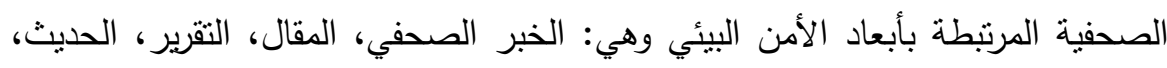
تحقيقق صحفي. • فئة المساحة: ينتم الأستعانة بهذه الفئة من أجل الكثف عن مسنتوى وحجم الأهتمام الذي

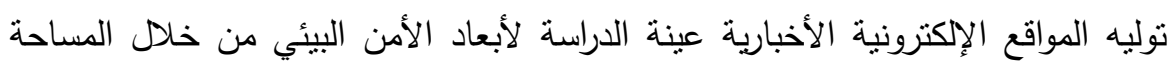
المخصصة لعرضها. • فئة عناصر التدعيم المرافقة للمادة الخبرية: العناصر التي تم استخدامها لتدعيم وتمييز موضوعات أبعاد الأمن البيئي بالوسائط المتعددة المختلفة وتتشل: صور ، ملف صوتي، ملف فيديو ، روابط إحالة. • فئة عناصر الإبراز المرافقة للمادة الخبرية: وهي العناصر التي تستخدمها المواقع الإلكترونية الإخبارية عينة الدراسة لإبراز وتمييز موضوعات أبعاد الأمن البيئي وتشمل الفئات التالية: تكبير وتصغير الموضوع، طباعة وحفظ الموضوع، أختصار ، متعلقات.

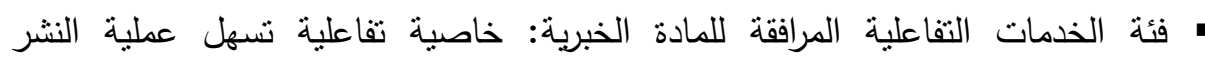
والمشاركة للمادة الخبرية والتفاعل بين جمهور الموقع الإخباري، وتشمل الفئات الآتية:

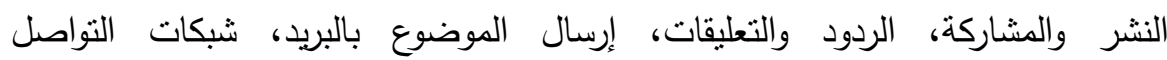
الإجتماعي. • فئة نوع التغطية: التغطية الإخبارية هي عملية تتبع الأخبار من مصادرها ومعرفة ما

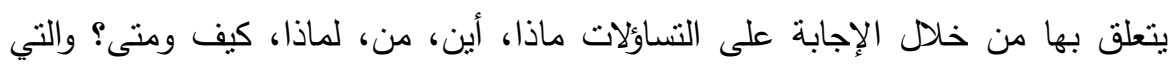

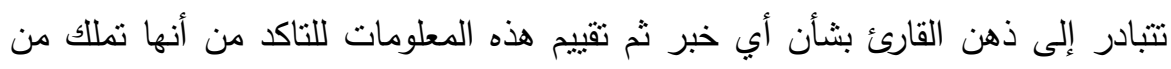

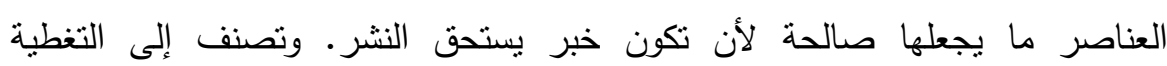
التفسيرية، التغطية التقريرية، التغطية التمهيدية. • فئة العناوين: هي العناوين المصاحبة للموضوعات المتعلقة بقضايا أبعاد الأمن البيئي

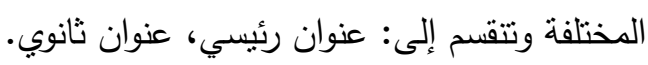


ثالثاً: النطبيق العملي للاراسة:

قام الباحثون بتحليل مضمون أربع مواقع إلكترونية إخبارية من خلال نطبيق الأسبوع

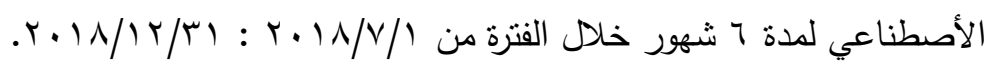

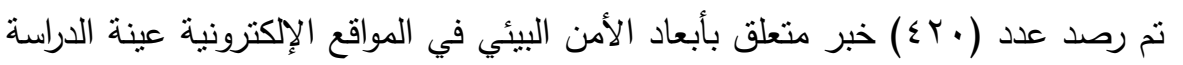

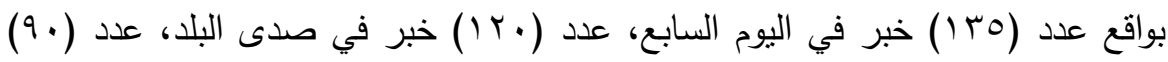
خبر في CNN وعدد (Vo) خبر في الجارديان.

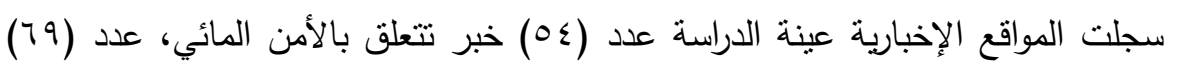

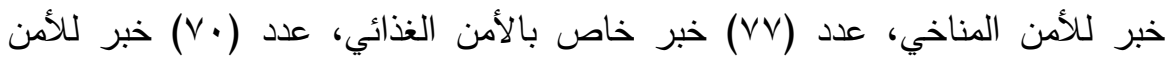
النووي، عدد (1) خبر للأمن البيولوجي، عدد (ro) خبر خاص بأمن الطاقة، وعدد (זr) خبر متعلق بأمن التتوع البيولوجي. تنبين للباحثون من خلال إستخدام أستمارة تحليل المضمون النتائج التالية التي من شأنها تجيب على أسئلة الدراسة: - كان أكثر موضوعات الأمن البيئي معالجة بالنسبة للمواقع الإلكترونية الإخبارية المحلية والعالمية هو مؤتمر التتوع البيولوجي حيث جاء بنسبة سه\% للمواقع المحلية في مقابل צr\% للمواقع العالمية. - فيما يتعلق بمصادر التحقيقات التي أعتمدت عليها كل من المواقع الإلكترونية الإخبارية المحلية والعالمية في التغطية الإخبارية فقد جاء مصدر "مندبون و مراسلون" في المرتبة المبن

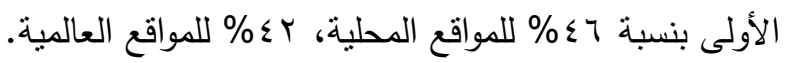

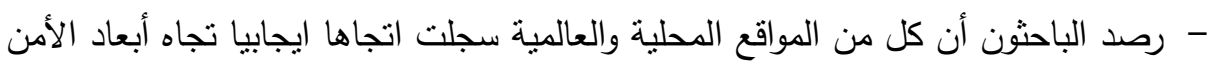

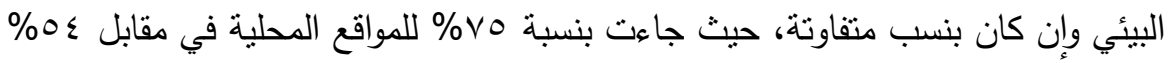
للمواقع العالمية.

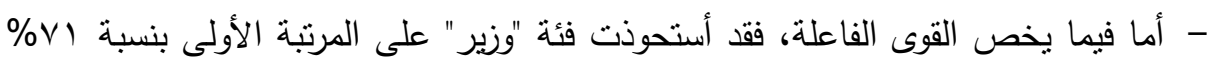
للمواقع المحلية ونسبة ء ب\% للمواقع العالمية. 
- كانت الأستمالات العقلية أكثر أنواع الأستمالات الإقناعية إستخداما من كلا المواقع

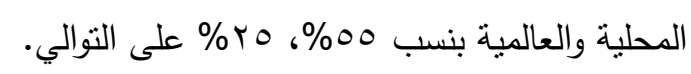

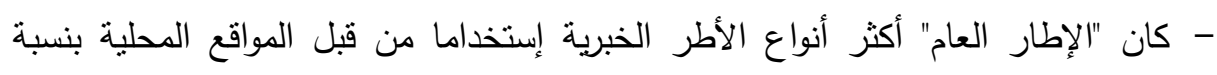

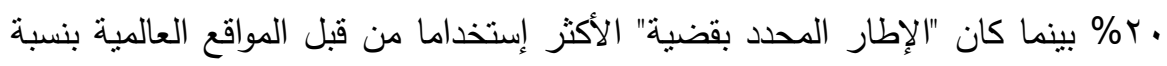

\section{\% r}

رابعاً: تقديم نموذج مقترح لموقع إلكتروني إخباري بيئي لمعالجة أبعاد الأمن البيئي.

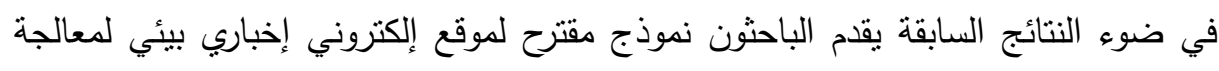

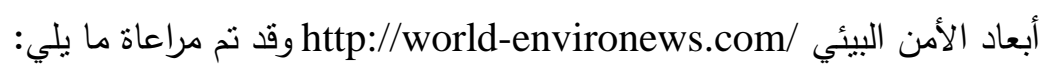

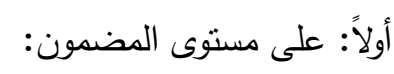

• تتوع مصادر التحقيقات التي يعتمد عليها الموقع في التغطية الإخبارية دون الإقتصار على التى

$$
\text { مصدر واحد وذللك على النحو التالي: }
$$

- مندبون ومراسلوان: ينبغى أن يتضمن الموقع الإخباري العديد من المندبون و المراسلوان

$$
\text { لسرعة تغطية الأحداث على كافة المستويات المحلية، الأقليمية و العالمية. }
$$

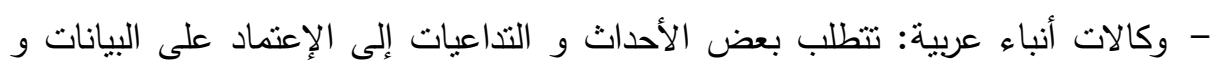

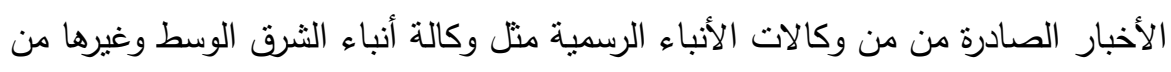

$$
\text { وكالات الأنباء العربية. }
$$

- وكالات أنباء عالمية: وذلك للأستفادة من التدفق الكثبر للمعلومات والأخبار التي تتيحه

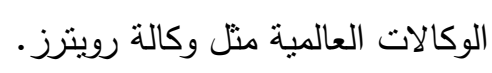

- الكتاب: لا يجب أن يعتمد الموقع الإخباري على نقل الخبر فقط و لكن يجب الإستفادة من

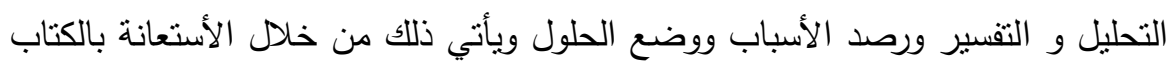

$$
\text { والخبراء المتخصصين. }
$$

وبذلك تتحقق التغطية الصحفية متعددة المصادر لما لها من دور كبير في تعزيز المصداقية

$$
\text { ونيل نقة القارئ بالمعلومات المنشورة. }
$$

• تعدد موضوعات التحقيقات التي تتتاول أبعاد الأمن البيئي بما يحقق التغطية الثمولية

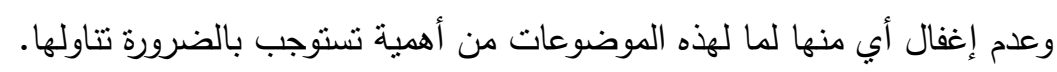


الأستفادة من وظائف الأطر الخبرية في معالجة أبعاد الأمن البيئي من حيث :

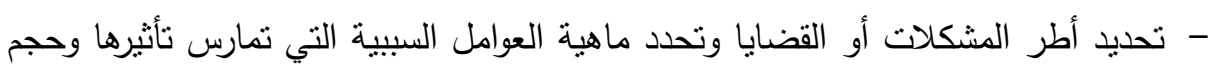
المكاسب والخسائر ويقاس ذلك من خلال القيم الثقافية العامة. - تحديد أسباب المشكلة، وتحديد الأبعاد التي احدثت المشكلة. - وضع أحكام أخلاقية لتلك العوامل السببية وتأثنراتها. - تقترح الأطر سبل معالجة المشكلات أو القضايا والتتبؤ بتأثيراتها المحتملة.

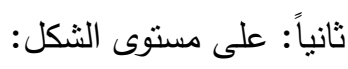
() نتوع الأثكال الصحفية التي يعنمد عليها الموقع في التغطية الإخبارية دون الإقتصار على شكل صحفي واحد و ذلك على النحو التالي : الخبر الصحفي:حيث انه المهمة الأساسية للموقع الإخباري في نقل الأخبار لحظة حدوثها

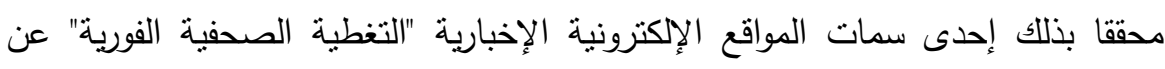
طريق بث الأخبار بشكل فوري ومتجد كذللك توفير خدمة Breaking News التي توفر الإنها

$$
\text { معلومات عن الأخبار الدفاجئة. }
$$

التقرير الصحفي: يوفر التقرير الصحفي مجموعة من المعارف والمعلومات حول الوقائع

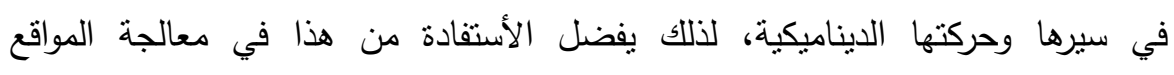

$$
\text { الإلكترونية الإخبارية لأبعاد الأمن البيئي. }
$$

المقال الصحفي: وذللك لشرح وتفسير الأحداث الجارية والتعليق عليها بما يكثف عن الإنف الإن

دلالاتها المختلفة.

• التحقيق الصحفي: بغرض البحث والتحري والأسنطلاع والتحليل لقضايا البيئة لمعرفة أسبابها ومسبياتها بهدف تقديم حلول لها أو عرض وجهة نظر حيالها، تدعمها الحقائق

$$
\text { والثواهد والإحصاءات. }
$$

بما يحقق الإعتماد على الأثكال الصحفية المختلفة من خلال الجانب الخبري وجانبي الرأي والتفسير لتقديم رؤية منكاملة للقارئ. 
r) تعدد الخدمات التفاعلية المرافقة للمادة الخبرية مثل إستخدمات خدمات التواصل

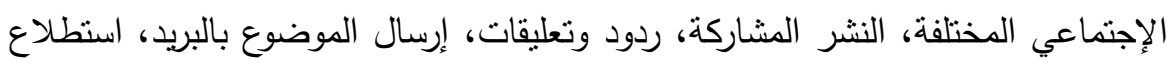

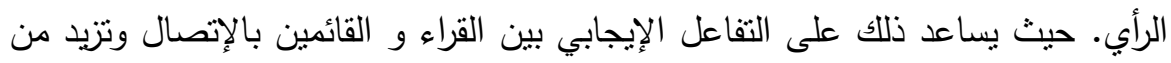
مشاركة القراء في أداء الأعمال الصحفية والرد على كل الأراء والمعلومات المنشورة. r) تتوع عناصر التدعيم المرافقة للمادة الخبرية التي نوفر العديد من الوسائل التفاعلية التي لتئي

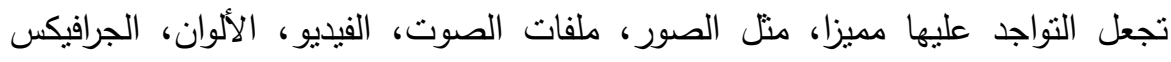
واللقطات المتحركة وهي أمور تفعل عملية الاتصال الصحفي بين الصحيفة وقرائها، وتتقل مئل

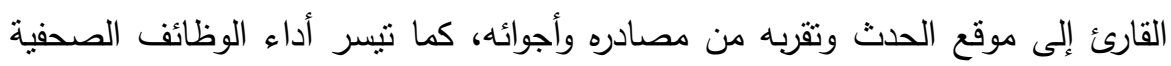
من إخبار وشرح وتقسير، فضلا عن القدرة على التحكم في طريقة العرض والأحجام والخلفيات والمساحات.

؛) تحقيق الثمولية في إستخدام أنواع محتلفة من التغطية الإخبارية سواء كانت تغطية

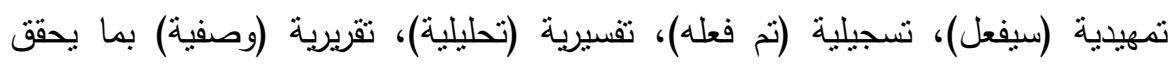
التغطية الثاملة والتفسيرية التي لا تقف عند الطابع الخبري المباشر أو التغطية التسجيلية، إنما تمتد لتركز على الأبعاد الإنسانية والتتاول الثامل لظواهر مرتبطة بالأمن البيئي وأسبابها وسبل حلها. 0) إتاحة الموقع للقراء التصفح بثلاث لغات "العربية، الإنجليزية، الفرنسية" بما يساعد على ملى مأل مخاطبة جنسيات وثقافات مختلفة.

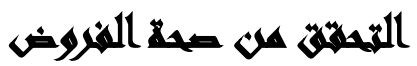

الفرض الأول: نوجد فروق ذات دلالة إحصائية بين المواقع الإكترونية الإخبارية المحلية

$$
\text { والعالمية في معالجة الأمن المائي. }
$$


جدول (1): اختبار كا` لتوضيح الفروق بين المواقع الإليكترونية الإخبارية المحلية والعالمية

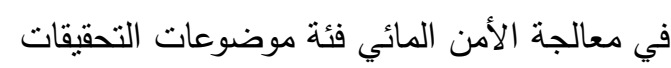

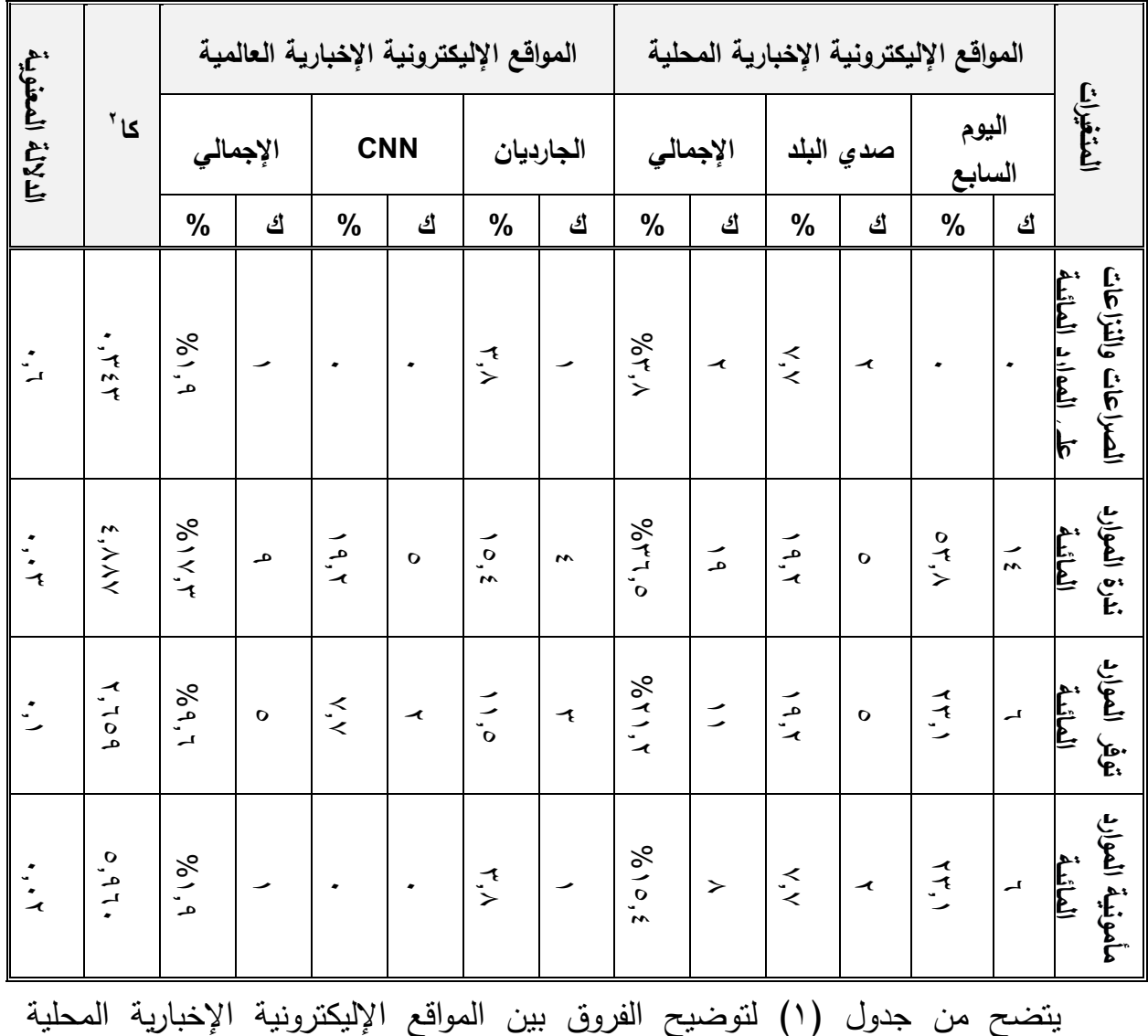

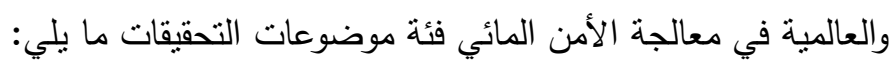
توجد فروق ذات دلالة إحصائية عند مستوى معنوية (0 . . •) لفئة ندرة الموارد المائية حيث

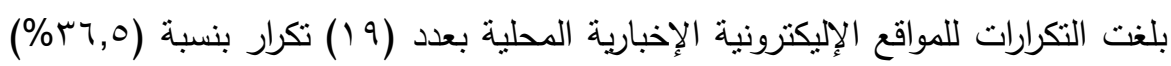

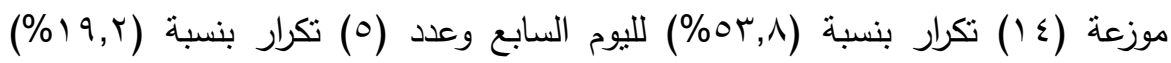

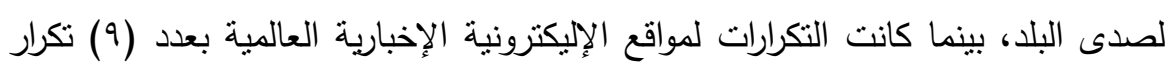


بنسبة (Y,

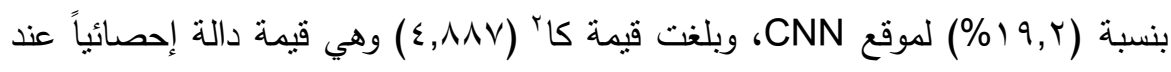
مستوى معنوية (0., •) لصالح المواقع الإليكترونية الإخبارية المحلية.

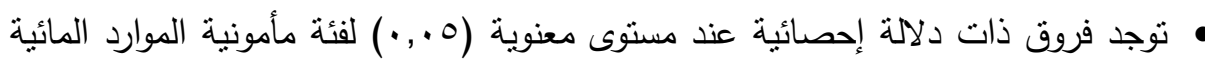

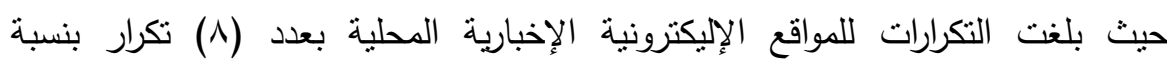

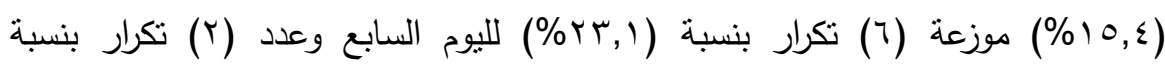

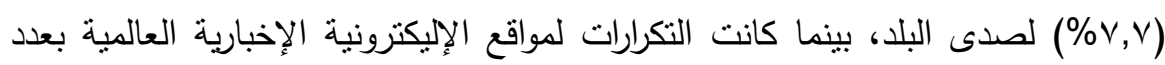

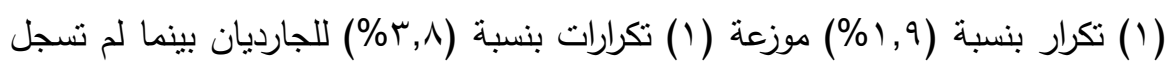

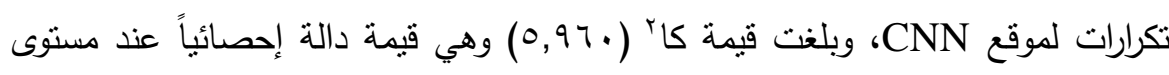
معنوية (0. . • ) لصالح المواقع الإليكترونية الإخبارية المحلية.

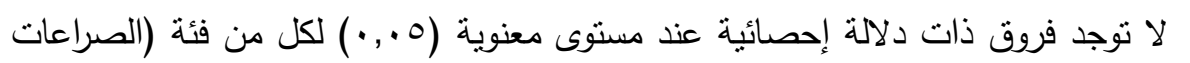

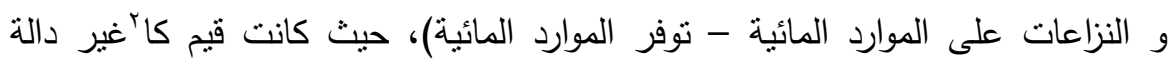

$$
\text { إحصائياً عند مستوى معنوية (0. . •)). }
$$

الفرض الثاني: نوجد فروق ذات دلالة إحصائية بين المواقع الإلكترونية الإخبارية المحلية والعالمية في معالجة الأمن المناخي. تولي. 
جدول (r): اختبار كا׳ لتوضيح الفروق بين المواقع الإليكترونية الإخبارية المحلية والعالمية

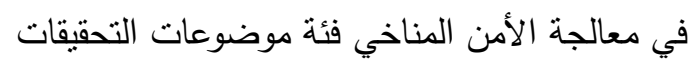

\begin{tabular}{|c|c|c|c|c|c|c|c|c|c|c|c|c|c|c|}
\hline \multirow{3}{*}{ 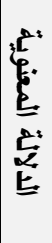 } & \multirow{3}{*}{$\tilde{a}$} & \multicolumn{6}{|c|}{ المواقع الإليكترونية الإخبارية العالمية } & \multicolumn{6}{|c|}{ المواقع الإليكترونية الإخبارية المحلية } & \multirow{3}{*}{$\underline{\underline{E}}$} \\
\hline & & \multicolumn{2}{|c|}{ الإجمالي } & \multicolumn{2}{|c|}{ CNN } & \multicolumn{2}{|c|}{ الجارديان } & \multicolumn{2}{|c|}{ الإجمالي } & \multicolumn{2}{|c|}{ صدي البلد } & \multicolumn{2}{|c|}{ السابع } & \\
\hline & & $\%$ & ك & $\%$ & ك & $\%$ & ك & $\%$ & ك & $\%$ & ك & $\%$ & ك & \\
\hline$\therefore$ & $\begin{array}{l}\dot{m} \\
\bar{z} \\
m \\
z\end{array}$ & 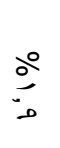 & - & - & - & $\dddot{z}$ & - & $\begin{array}{c}\frac{0}{10} \\
\frac{1}{y}\end{array}$ & 1 & • & - & $<$ & 1 & $\begin{array}{l}\text { E. } \\
\text { E. } \\
\underline{E} \\
\underline{E}\end{array}$ \\
\hline$\because$ & $\begin{array}{l}a \\
m \\
m\end{array}$ & $\begin{array}{l}0 \\
\vdots \\
0 \\
0\end{array}$ & z & $\ddot{1}$ & $>$ & $\stackrel{0}{0}$ & $m$ & $\begin{array}{l}0 \\
\vdots \\
\vdots \\
0\end{array}$ & ○ & ع & 1 & $<$ & 1 & $\begin{array}{l}\vec{E} \\
\vec{E} \\
\underline{E} \\
\underline{E}\end{array}$ \\
\hline 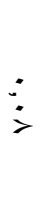 & $\begin{array}{l}\because \\
\ddot{z} \\
\overrightarrow{>}\end{array}$ & 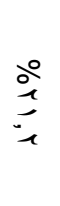 & こ & $\dot{y}$ & $>$ & 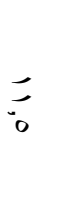 & 1 & $\frac{8}{3}$ & مَ & $\underline{z}$ & + & $:$ & $\overline{1}$ & 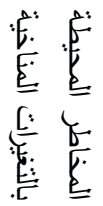 \\
\hline$\because$ & $\ddot{z}$ & $\stackrel{0}{\circ}$ & $\circ$ & $=$ & $\checkmark$ & $<$ & 1 & $\begin{array}{l}\stackrel{0}{0} \\
0 \\
0 \\
0\end{array}$ & $\bar{z}$ & $\dot{\xi}$ & $>$ & $\vec{a}$ & $\circ$ & 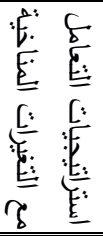 \\
\hline
\end{tabular}

يتضح من الجدول (r) لتوضيح الفروق بين المواقع الإلكترونية الإخبارية المحلية

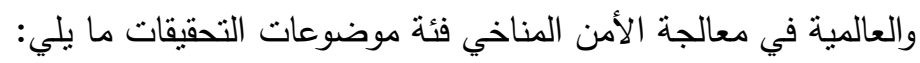
توجد فروق ذات دلالة إحصائية عند مسنوى معنوية (0.,•) لموضوع استراتيجيات

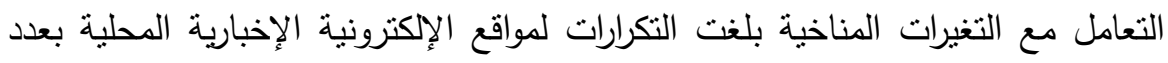

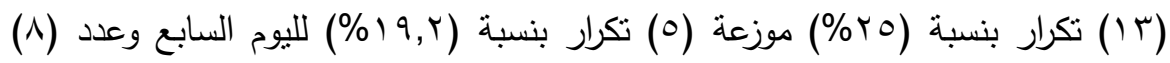


تكرارات بنسبة (^, • ץ\%) لصدى البلد، بينما كانت التكرارات لمواقع الإلكترونية الإخبارية

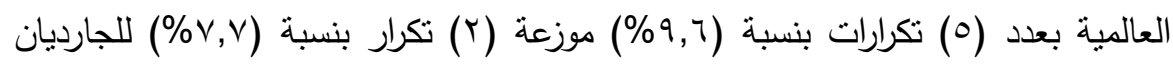

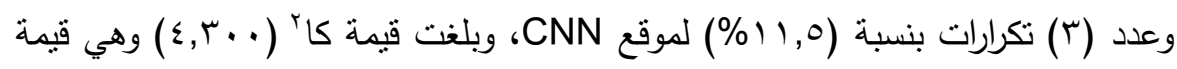
دالة إحصائياً عند مستوى معنوية (0. ., •) لصالح المواقع الإليكترونية الإخبارية المحلية.

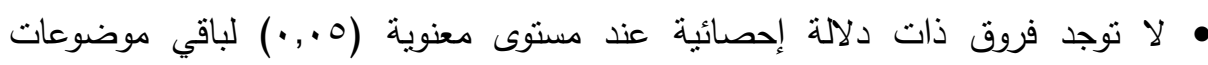
التحقيقات الأخرى حيث كانت قيم كا؟ غير دالة إحصائياً عند مستوى معنوية (0. . • ). الفرض الثالث: توجد فروق ذات دلالة إحصائية بين المواقع الإككترونية الإخبارية المحلية والعالمية في معالجة الأمن الغذائي. جلول (ץ): اختبار كا` لتوضيح الفروق بين المواقع الإليكترونية الإخبارية المحلية والعالمية

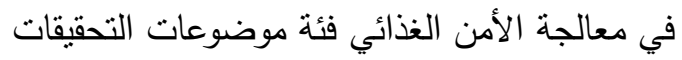

\begin{tabular}{|c|c|c|c|c|c|c|c|c|c|c|c|c|c|c|}
\hline \multirow{3}{*}{ 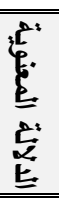 } & \multirow{3}{*}{$\tilde{n}$} & \multicolumn{6}{|c|}{ المواقع الإليكترونية الإخبارية العالمية } & \multicolumn{6}{|c|}{ المواقع الإليكترونية الإخبارية المحلية } & \multirow{3}{*}{$\underline{\underline{E}}$} \\
\hline & & \multicolumn{2}{|c|}{ الإجمالي } & \multicolumn{2}{|c|}{ CNN } & \multicolumn{2}{|c|}{ الجارديان } & \multicolumn{2}{|c|}{ الإجمالي } & \multicolumn{2}{|c|}{ صدي البلد } & \multicolumn{2}{|c|}{ اليوم السابع } & \\
\hline & & $\therefore$ & S & $\%$ & ك & $\%$ & S & $\%$ & 5 & $\%$ & s & $\%$ & S & \\
\hline$\therefore$ & $\begin{array}{l}\ddot{O}_{0} \\
\dot{0}\end{array}$ & 1 & $<$ & in & $m$ & 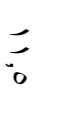 & 1 & $\because$ & $\circ$ & 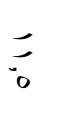 & 1 & $<$ & 1 & : \\
\hline$\therefore$ & בَ & $\because$ & - & $\dddot{q}$ & - & • & - & $<$ & m & $<$ & e & $<$ & 1 & 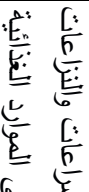 \\
\hline$\dot{\ddot{1}}$ & $\begin{array}{l}\ddot{m} \\
\hat{o} \\
a\end{array}$ & $\therefore$ & $>$ & $=$ & 1 & 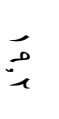 & $\circ$ & $\ddot{z}$ & $\beth$ & $\begin{array}{l}1 \\
-5\end{array}$ & $<$ & $\stackrel{1}{a}$ & مـ & 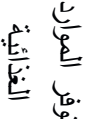 \\
\hline$\because$ & $\because$ & 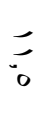 & + & $=$ & 1 & 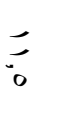 & 1 & $\begin{array}{l}7 \\
? \\
0\end{array}$ & $?$ & $\begin{array}{l}1 \\
0 \\
0\end{array}$ & $<$ & $:$ & $\overline{1}$ & 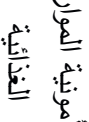 \\
\hline$\therefore$ & 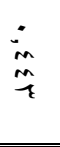 & $<$ & $m$ & ك & 1 & $\dddot{7}$ & - & ك & + & $\therefore$ & $m$ & $<$ & 1 & 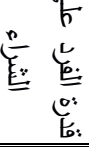 \\
\hline
\end{tabular}


يتضح من الجدول (r) لتوضيح الفروق بين المواقع الإليكترونية الإخبارية المحلية

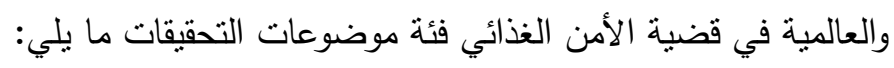

•توجد فروق ذات دلالة إحصائية عند مستوى معنوية (0. . •) لفئة توفر الموارد الغذائية

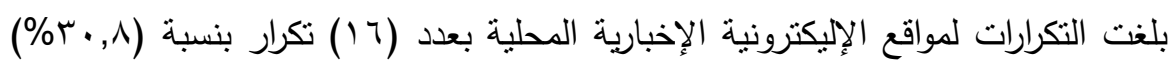

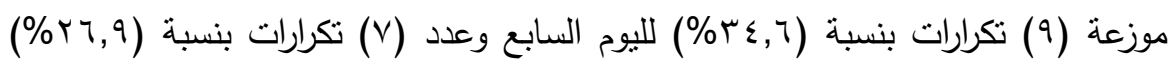

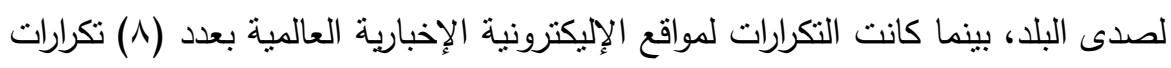

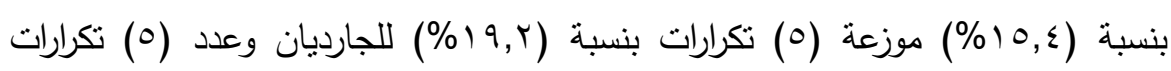

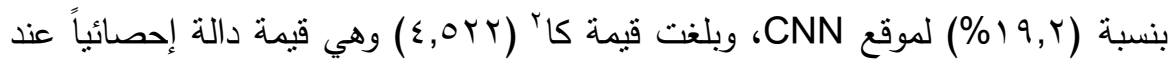
مسنوى معنوية (0. . . •) لصالح المواقع الإليكترونية الإخبارية المحلية. توجد فروق ذات دلالة إحصائية عند مسنوى معنوية (ه., •) لفئة مأمونية الموارد الغذائية

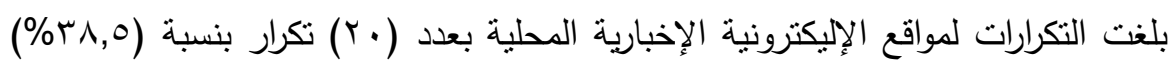

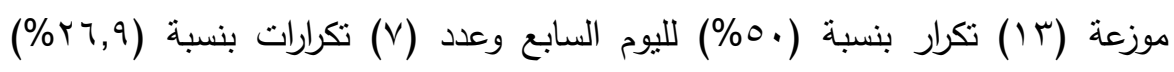
لصدى البلد، بينما لم تسجل نكرارات لمواقع الإليكترونية الإخبارية العالمية، بينما كانت

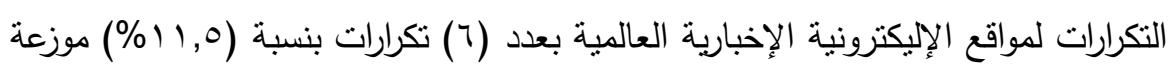

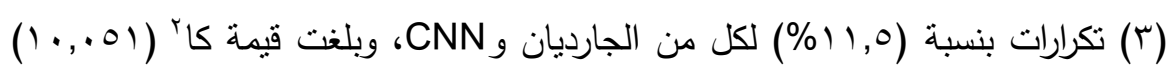
وهي قيمة دالة إحصائياً عند مستوى معنوية (0. (. • ) لصالح المواقع الإكترونية الإخبارية المحلية. • لا توجد فروق ذات دلالة إحصائية عند مستوى معنوية (0.,.) لكل من فئة (اتفاقية

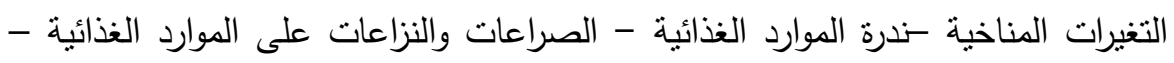

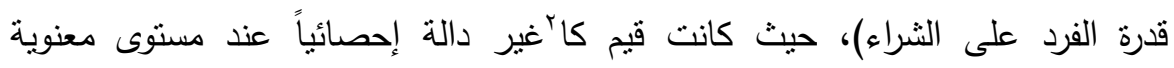
$\cdot(\cdot, \cdot 0)$ بينما لم تسجل تكرارات لباقي فئات موضوعات التحقيقات لكل من المواقع الإليكترونية الإخبارية المحلية والمواقع الإليكترونية الإخبارية العالمية. 
الفرض الرابع : توجد فروق ذات دلالة إحصائية بين المواقع الإكترونية الإخبارية المحلية و

$$
\text { العالمية في معالجة الأمن النووي (الإثعاعي). }
$$

جدول (؛): اختبار كا` لتوضيح الفروق بين المواقع الإلكترونية الإخبارية المحلية والعالمية

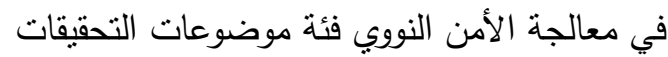

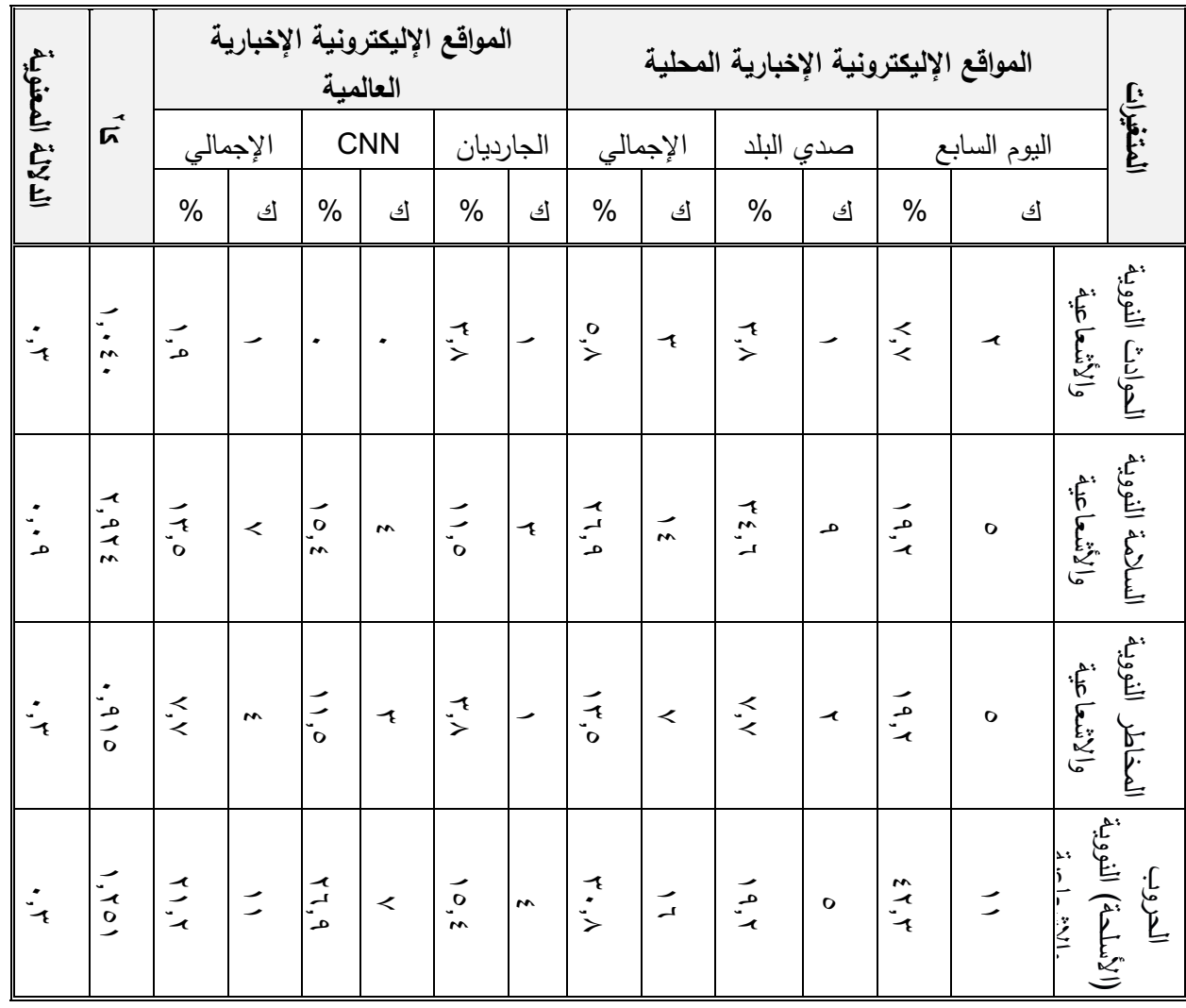

يتضح من الجدول (ع) لتوضيح الفروق بين المواقع الإلكثرونية الإخبارية المحلية والعالمية في معالجة الأمن النووي فئة موضوعات التحقيقات ما يلي: لا توجد فروق ذات

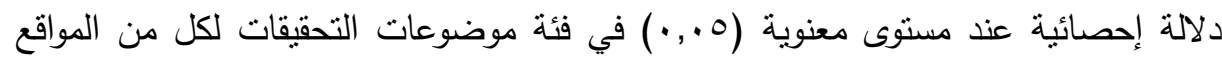

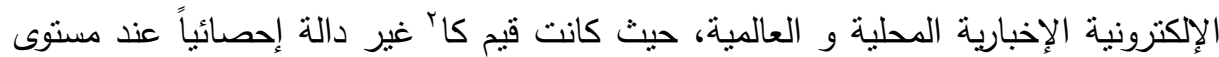
معنوية (0., (•). (-). 
الفرض الخامس: توجد فروض ذات دلالة إحصائية بين المواقع الإليكترونية الإخبارية المحلية والعالمية في قضية الأمن البيولوجي. جدول (•): اختبار كا` لتوضيح الفروق بين المواقع الإلكترونية الإخبارية المحلية والعالمية

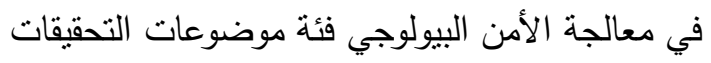

\begin{tabular}{|c|c|c|c|c|c|c|c|c|c|c|c|c|c|c|}
\hline \multirow{3}{*}{ 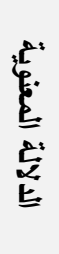 } & \multirow{3}{*}{$\bar{n}$} & \multicolumn{6}{|c|}{ المواقع الإليكترونية الإخبارية العالمية } & \multicolumn{6}{|c|}{ المواقع الإليكترونية الإخبارية المحلية } & \multirow{3}{*}{$\underline{\underline{E}}$} \\
\hline & & \multicolumn{2}{|c|}{ الإجمالي } & \multicolumn{2}{|c|}{ CNN } & \multicolumn{2}{|c|}{ 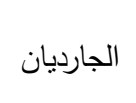 } & \multicolumn{2}{|c|}{ ال الإجمالي } & \multicolumn{2}{|c|}{ صدي البلد } & \multicolumn{2}{|c|}{ اللسابع } & \\
\hline & & $\%$ & ك & $\%$ & ك & $\%$ & ك5 & $\%$ & ك & $\%$ & ك & $\%$ & ك & \\
\hline$\vdots$ & 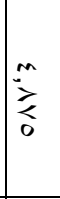 & 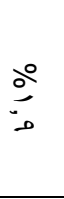 & - & $\ddot{z}$ & - & - & - & $\begin{array}{l}0 \\
\frac{1}{1} \\
0 \\
0\end{array}$ & $<$ & $\hat{z}$ & + & $\dddot{7}$ & - & 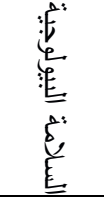 \\
\hline$\dot{\vdots}$ & $\begin{array}{l}1 \\
\vdots \\
0\end{array}$ & $\stackrel{\circ}{\vdots}$ & - & - & - & - & - & $\begin{array}{l}\stackrel{0}{0} \\
\stackrel{0}{>}\end{array}$ & 1 & 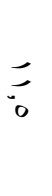 & 1 & . & . & 点 \\
\hline$\ddot{>}$ & $\because$ & $\begin{array}{l}\stackrel{0}{0} \\
\vdots\end{array}$ & 千 & 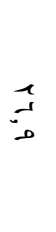 & $<$ & $\underline{1}$ & + & $\begin{array}{l}\stackrel{0}{0} \\
\vdots 1 \\
50\end{array}$ & m & 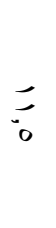 & 1 & $\ddot{q}$ & $=$ & 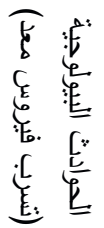 \\
\hline$\therefore$ & $\dot{\ddot{z}}$ & 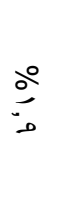 & - & . & • & $i$ & - & $\frac{0}{i}$ & 1 & - & - & $<$ & e & 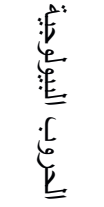 \\
\hline
\end{tabular}


يتضح من جدول (0) لتوضيح الفروق بين المواقع الإليكترونية الإخبارية المحلية

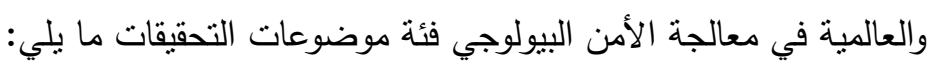

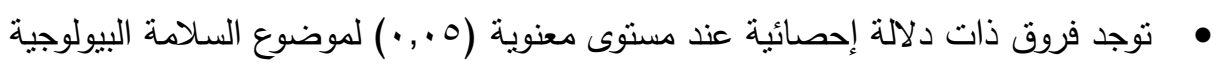

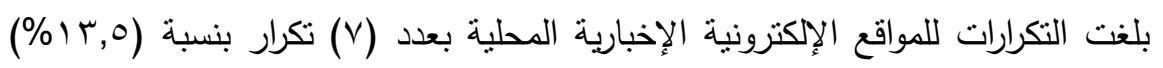

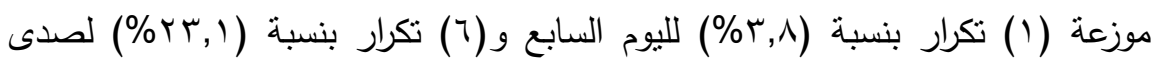

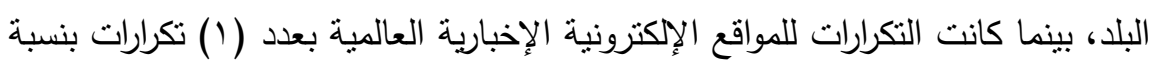

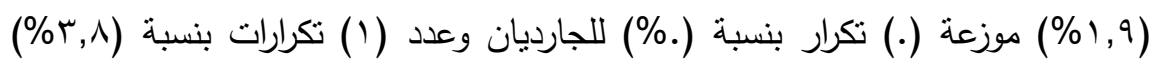

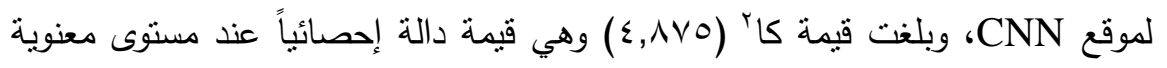
(0. (•) ) لصالح المواقع الإلكترونية الإخبارية المحلية.

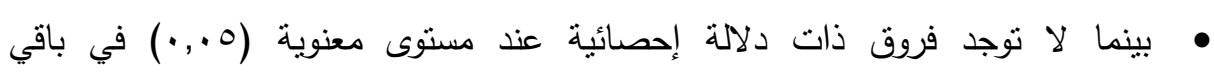

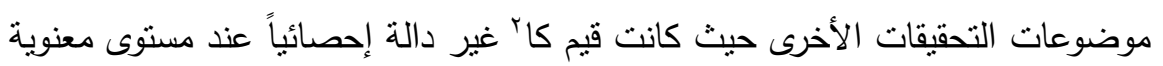
$\cdot(\cdot, 0)$

الفرض السادس: توجد فروق ذات دلالة إحصائية بين المواقع الإككترونية الإخبارية المحلية و العالمية في معالجة أمن الطاقة. 
جلول (†): اختبار كا` لتوضيح الفروق بين المواقع الإليكترونية الإخبارية المحلية والعالمية

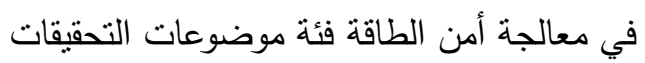

\begin{tabular}{|c|c|c|c|c|c|c|c|c|c|c|c|c|c|c|}
\hline \multirow{3}{*}{ 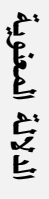 } & \multirow{3}{*}{$\tilde{n}$} & \multicolumn{6}{|c|}{ المواقع الإليكترونية الإخبارية العالمية } & \multicolumn{6}{|c|}{ المواقع الإليكترونية الإخبارية المحلية } & \multirow{3}{*}{$\underline{\underline{E}}$} \\
\hline & & \multicolumn{2}{|c|}{ الإجمالي } & \multicolumn{2}{|c|}{ CNN } & \multicolumn{2}{|c|}{ الجارديان } & \multicolumn{2}{|c|}{ الإجمالي } & \multicolumn{2}{|c|}{ صدي البلد } & \multicolumn{2}{|c|}{ اليوم السابع } & \\
\hline & & $\%$ & ك5 & $\%$ & ك & $\%$ & ك & $\%$ & ك ك & $\%$ & 5 & $\%$ & ك & \\
\hline$\therefore$ & $\frac{1}{i}$ & \begin{tabular}{l}
0 \\
\hdashline
\end{tabular} & o & $<$ & 1 & $=$ & 1 & $\begin{array}{l}\stackrel{0}{<} \\
<\end{array}$ & m & $=$ & 1 & $\dddot{q}$ & - & 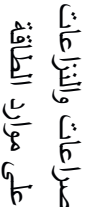 \\
\hline$\therefore$ & $\begin{array}{l}\dot{z} \\
\overline{1}\end{array}$ & $\underset{<}{\stackrel{0}{<}}$ & m & $<$ & 1 & $<$ & a & $\begin{array}{l}\stackrel{0}{ } \\
\Rightarrow \\
\Rightarrow\end{array}$ & $\circ$ & - & - & $\vec{a}$ & o & 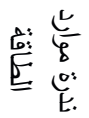 \\
\hline$\because$ & 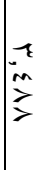 & $\begin{array}{l}\stackrel{0}{1} \\
\vdots \\
\vdots\end{array}$ & $\overline{7}$ & $\underline{z}$ & + & $\underset{\square}{ \pm}$ & $<$ & 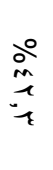 & $\xi$ & $\begin{array}{l}1 \\
? \\
0\end{array}$ & ? & $\vec{a}$ & z & 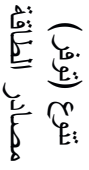 \\
\hline
\end{tabular}

يتضح من الجدول (†) لتوضيح الفروق بين المواقع الإليكترونية الإخبارية المحلية

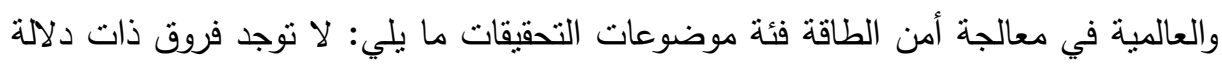

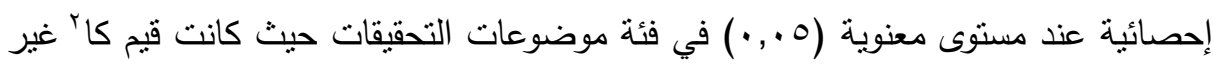
دالة إحصائياً عند مستوى معنوية (0. . •).

الفرض السابع : توجد فروق ذات دلالة إحصائية بين المواقع الإكترونية الإخبارية المحلية

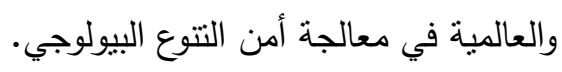


جدول (V): اختبار كا` لتوضيح الفروق بين المواقع الإكترونية الإخبارية المحلية والعالمية

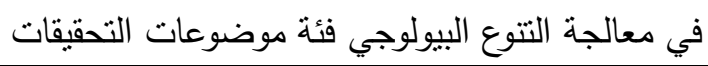

\begin{tabular}{|c|c|c|c|c|c|c|c|c|c|c|c|c|c|c|}
\hline \multirow{3}{*}{ 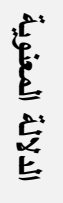 } & \multirow{3}{*}{$\hat{n}$} & \multicolumn{6}{|c|}{ المواقع الإليكترونية الإخبارية العالمية } & \multicolumn{6}{|c|}{ المواقع الإليكترونية الإخبارية المحلية } & \multirow{3}{*}{$\underline{\underline{E}}$} \\
\hline & & \multicolumn{2}{|c|}{ الإجمالي } & \multicolumn{2}{|c|}{$\mathrm{CNN}$} & \multicolumn{2}{|c|}{ الجارديان } & \multicolumn{2}{|c|}{ الإجمالي } & \multicolumn{2}{|c|}{ صدي البلا } & \multicolumn{2}{|c|}{ اليوم السابع } & \\
\hline & & $\%$ & ك & $\%$ & ك & $\%$ & ك & $\%$ & ك & $\%$ & ك & $\%$ & ك5 & \\
\hline$\because$ & $\begin{array}{l}< \\
⿱ 亠 乂 \\
⿱ 亠 乂\end{array}$ & $\begin{array}{l}\stackrel{0}{0} \\
\vdots \\
\vdots \\
0\end{array}$ & $\bar{m}$ & $\stackrel{1}{m}$ & م & $\ddot{0}$ & $\circ$ & $\begin{array}{l}80 \\
0 \\
0 \\
7 \\
7\end{array}$ & $\hat{z}$ & $\overrightarrow{3}$ & $\exists$ & $\vec{m}$ & ¿ & 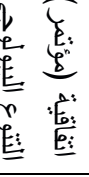 \\
\hline$\because$ & $\vdots$ & $\frac{0}{\circ}$ & ? & o & m & $\underline{z}$ & + & $\frac{0}{\circ}$ & ? & $\stackrel{0}{a}$ & $\circ$ & $\because$ & $\circ$ & 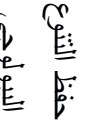 \\
\hline$\dot{\square}$ & $\vdots$ & $\stackrel{\circ}{\because}$ & - & • & • & - & • & $\overbrace{}^{\circ}$ & - & $\cdot$ & $\cdot$ & $\ddot{7}$ & - & 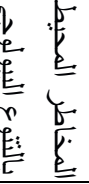 \\
\hline 1 & 1 & $\stackrel{\circ}{\vdots}$ & $\cdot$ & $\cdot$ & • & $\cdot$ & $\cdot$ & $\stackrel{0}{\circ}$ & • & • & • & • & & 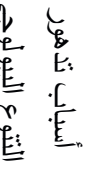 \\
\hline
\end{tabular}

يتضح من جدول (V) لتوضيح الفروق بين المواقع الإليكترونية الإخبارية المحلية والعالمية في معالجة أمن التتوع البيولوجي فئة موضوعات التحقيقات ما يلي:

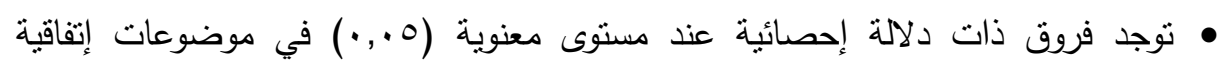

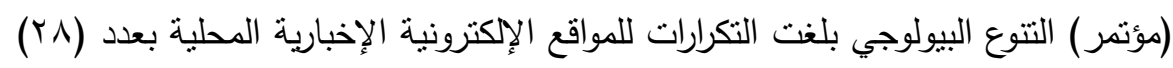

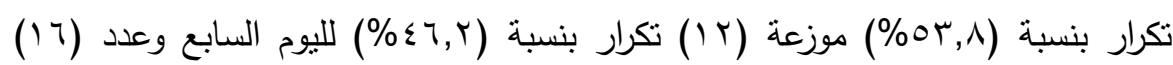
تكرار بنسبة (1,1\%) لصدى البلد، بينما كانت التكرارات للمواقع الإلكترونية الإخبارية

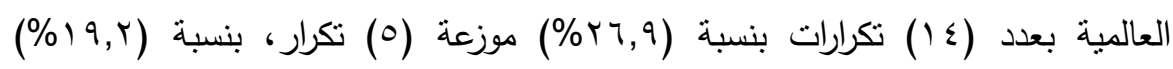

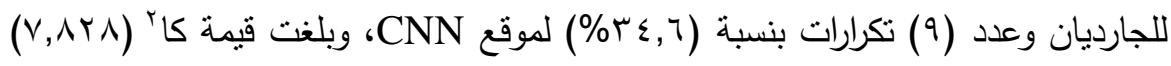


وهي قيمة دالة إحصائياً عند مستوى معنوية (0. . • ) لصالح المواقع الإكترونية الإخبارية المحلية. لا نوجد فروق ذات دلالة إحصائية عند مستوى معنوية (0.,.) في موضوعات (حفظ

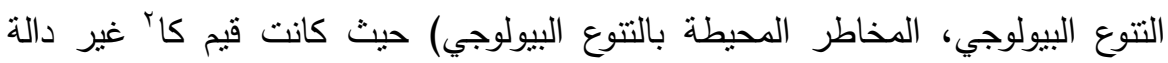
إحصائياً عند مستوى معنوية (0. . . •).

•م تسجل تكرارات لباقي موضوعات التحقيقات الأخرى لكل من المواقع الإلكترونية الأخبارية المحلية والعالمية.

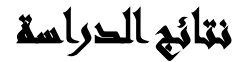

أسفرت الدراسة عن النتائج التالية: • صحة الفرض الأول: توجد فروق ذات دلالة إحصائية عند مستوى معنوية (0.,. ) بين المواقع الألكترونية الإخبارية المحلية والعالمية في معالجة الأمن المائي. • عدم صحة الفرض الثاني: توجد فروق ذات دلالة إحصائية عند مستوى معنوية (0., •) بين المواقع الأكترونية الإخبارية المحلية والعالمية في معالجة الأمن المناخي. توردي.

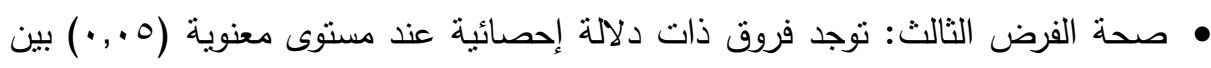
المواقع الألكترونية الإخبارية المحلية والعالمية في معالجة الأمن الغذائي. عدم صحة الفرض الرابع: توجد فروق ذات دلالة إحصائية عند مستوى معنوية (0.,. •) بين المواقع الأكترونية الإخبارية المحلية والعالمية في معالجة الأمن النووي.

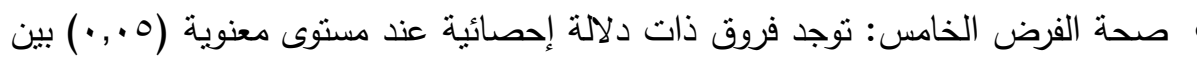
المواقع الأكترونية الإخبارية المحلية والعالمية في معالجة الأمن البيولوجي. صحة الفرض السادس: نوجد فروق ذات دلالة إحصائية عند مستوى معنوية (ه ., •) بين الإني المواقع الأكترونية الإخبارية المحلية والعالمية في معالجة أمن الطاقة. 
• صحة الفرض السابع: نوجد فروق ذات دلالة إحصائية عند مستوى معنوية (0., .) بين المواقع الألكترونية الإخبارية المحلية والعالمية في معالجة أمن التتوع البيولوجي.

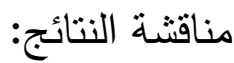

متصدرت الصصادر "المندبون والمراسلون" المرتبة الأولى لكل من المواقع الإلكترونية

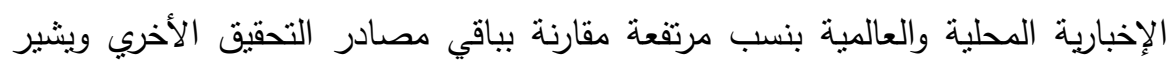

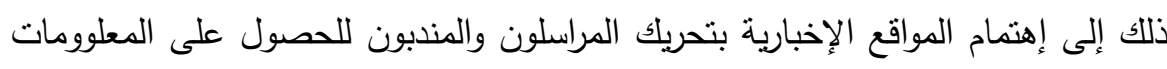

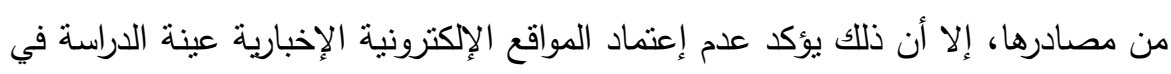

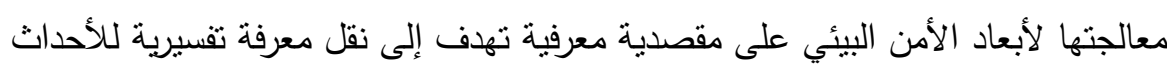
و تقدم للمتلقي الأسباب المختلفة.

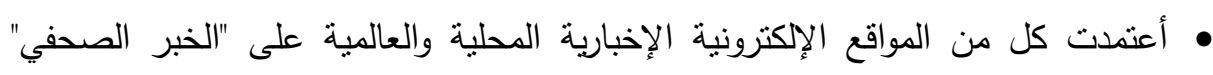

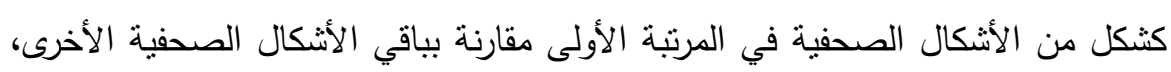

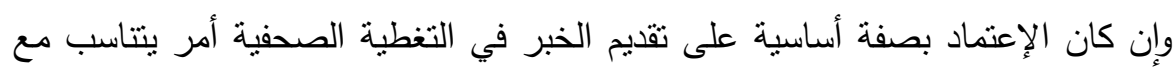

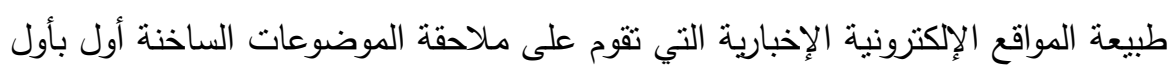

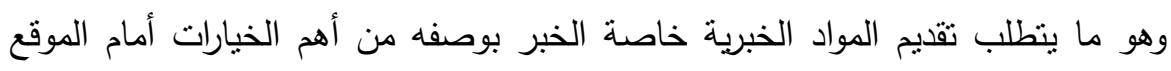

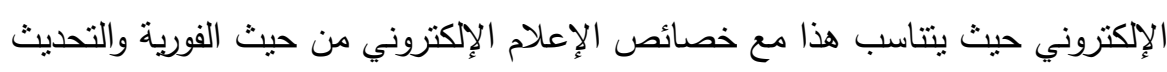

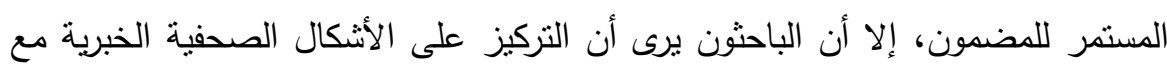

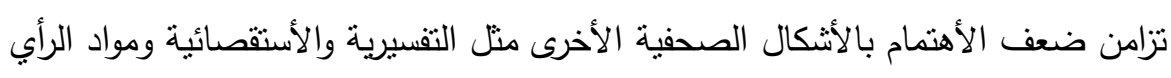

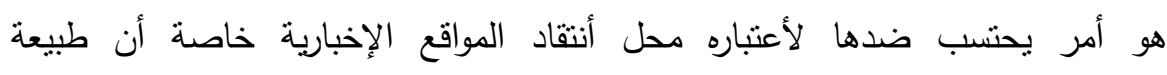

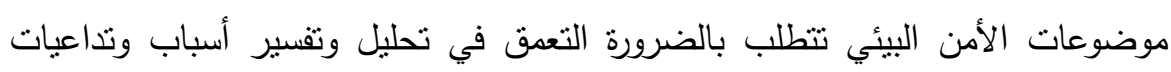
القضايا المثارة المرتبطة بالأمن البيئي.

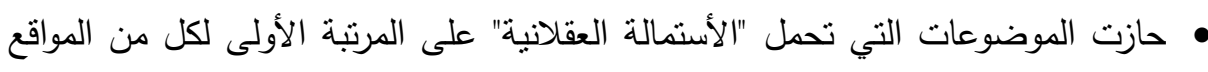

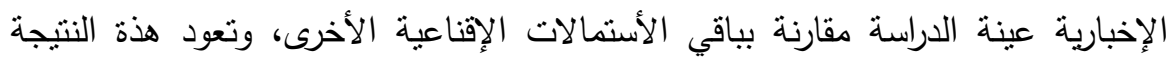

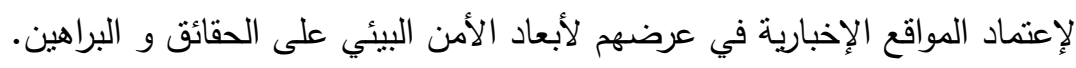

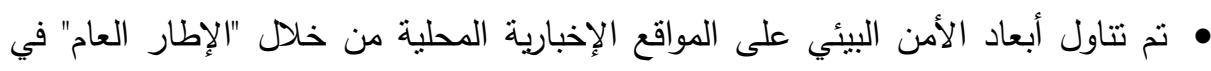

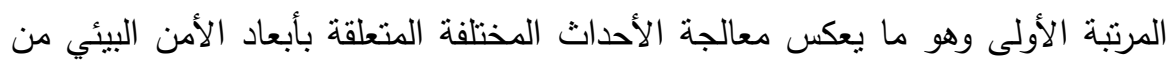


خلال النظرة الكلية للأزمة بأبعادها المختلفة دون التعمق، فيما أستخدم المواقع الإلكترونية الإخبارية العالمية "الإطار المحدد" في المرتبة الأولى مركزا في عرض أبعادها

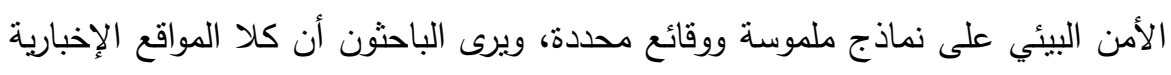

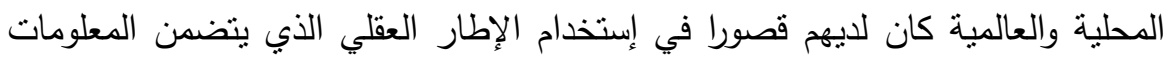
الأساسية كذلك تقديم الأسباب والحلول. وتعكس النتائج الخاصة بالأطر أختلافا واضحا بين المواقع عينة الدراسة ينبع من مجموعة من العوامل وليس من الاتجاه السياسي للادولة

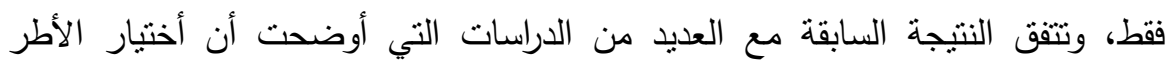
الاخبارية لا يكون وفقا على الروية السياسية فقط وإنما يكون نتاجا لعوامل سياسية وأقتصادية وثقافية تتفاعل جميعا لتحكم رؤية القائم بالأتصال وإنتقائه للأطر المبانية المستخدمة في التتاول وهذا ما تفترضه نظرية الأطر من حيث التركيز على بعض جوانب الوقائع

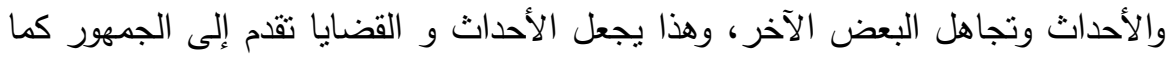
يراها الإعلاميون وليست كما تحدث في واقع الحياه، حيث يعيد الإعلاميون إنتاجها وتقديمها للرأي العام وفقا للتوجه السياسي الذي يتبناه هؤلاء الإعلاميون. أوضحت النتائج تقوق الإتجاه الإيجابي لكل من المواقع الإلكترونية الإخبارية المحلية

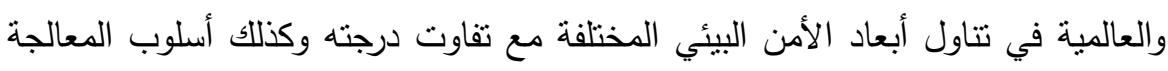
الإخبارية في الحالات المختلفة.

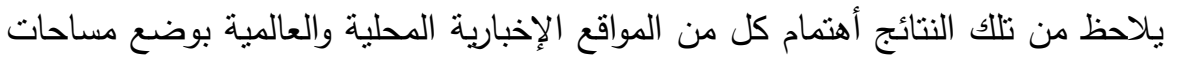

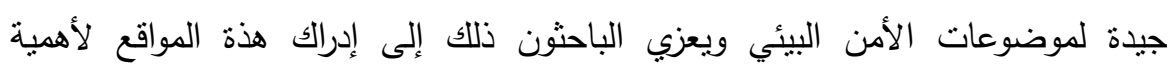
الموضوعات المتعلقة بأبعاد الأمن البيئي. أظهرث نتائج الدراسة التحليلية أن كل من المواقع الإكترونية الإخبارية المحلية والعالمية العبية

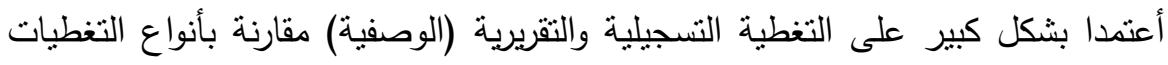

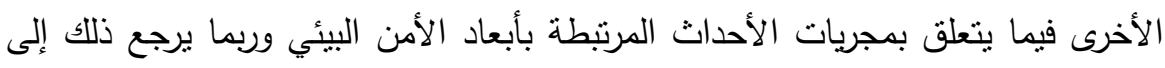

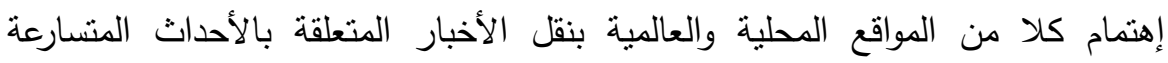
المرتبطة بأبعاد الأمن البيئي وتسجيل ووصف مجرياتها وتداعياتها، في المقابل كان هناك بالك 
قصورا في الإعتماد على التغطية التقسيرية التحليلية التي تعتمد على جمع المعلومات المساعدة أو التفسيرية إلى جانب الحقائق الأساسية لقصص إخبارية بهدف تفسير الخبر وشرحه للقراء.

• أستطاع القائم بالأتصال تحقيق الفرض الأساسي للنظرية الذي يقول بأن الوقائع والأحداث

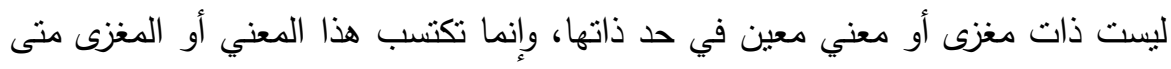
وضعت في إطار أو سياق يتفق مع الدركات الإجتماعية، وينسم هذا الإطار بالتنظيم

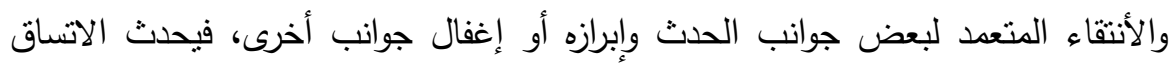

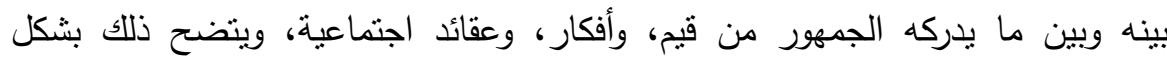

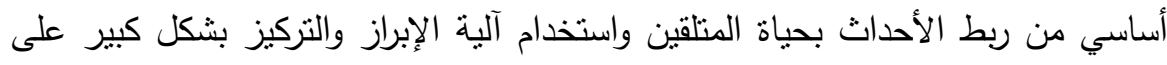
مستوى الوقائع التي يعرضها ثم ينتقل إلى الاستخلاص والأستنتاج لإحداث التأثنير

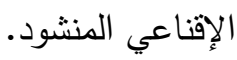

\section{تروسياهت التصراسة}

بناء على نتائج الدراسة يقدم الباحثون التوصيات التالية :

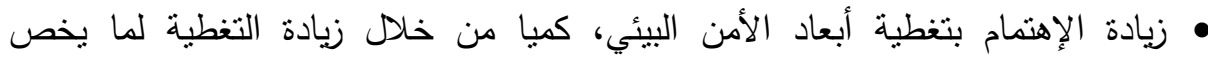

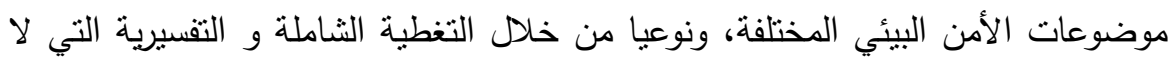
تقف عند الطابع الخبري المباشر، أو التغطية التسجيلية، إنما تمتد للتركز على الأبعاد الإنسانية والتتاول الثامل لظواهر مرتبطة بالأمن البيئي وأسبابها وسبل حلها. • دعوة مواقع الدراسة إلى التغطية الثمولية لموضوعات الأمن البيئي المختلفة وعدم إغفال أي منها، لما لهذه الموضوعات من أهمية تستوجب بالضرورة الفى تتاولها.

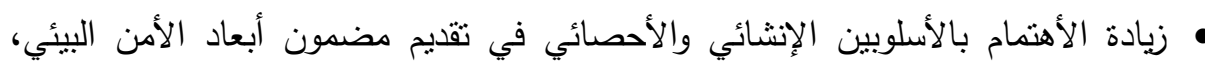
وعدم الأقتصار على أسلوب سرد المعلومات.

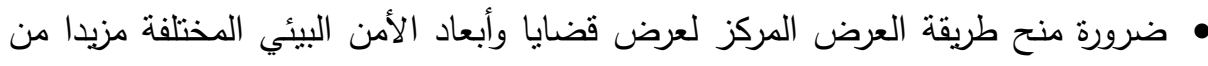

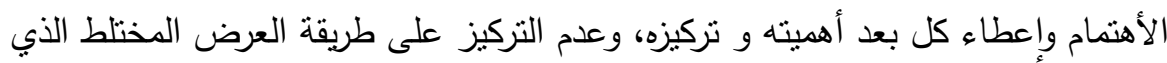
قد يضعف موضوع على حساب موضوع آخر . 
•العمل على تطوير الموقع المقترح لمواكبة التقنيات التكنولوجية الحديثة، كذلك تفعيل خدمة التصفح باللغات المختلفة.

\section{المراليع}

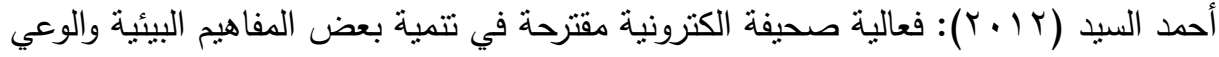

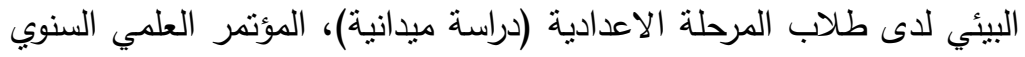

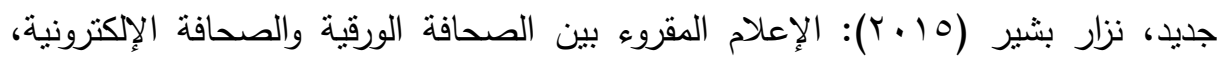 طا، دار الإعصار العلمي للنشر والتوزيع، عمان.
جمال أحمد (9 . . r): أطر إنتاج الخطاب الخبري في المواقع الإلكترونية في الأزمات الدولية:

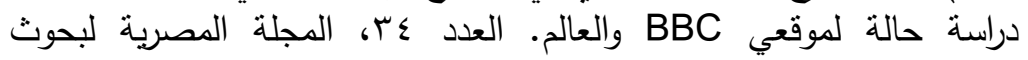

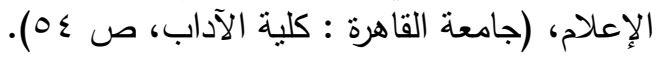

Allenby B. R. (2000): Environmental Security; Concept and Implementation. International Political Science Review, 21:5-21.

Colonel W. Chirs King (2000): Understanding International Environmental Security: A strategic Miliarity Perspective. Georgia Army Environmental Policy Institute, p.15.

Dabelko G. D. (1996): Environmental Security: Issues of Concept and Redefination. Environment and Security. 1(1): 23:49.

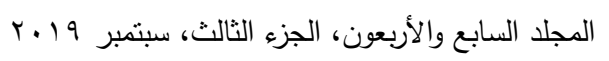


Da Nang, Viet Nam: Environmental Security: Dimensions and Priorities, 54 ${ }^{\text {th }}$ GEF Council Meeting, 2018.

Elizabeth L. Chalecki: Environmental Security: A case study of climate Change. Politic Institute for studies in Development, Environment and security, p2 Assecced 17/10/2018, www.bvsde.paho.org/bvsacd/cd68/EChalecki.pdf

Gamson William (1998): News As Framing. ABC: American Behavioral Scientist, Vol.(33), no.(2), pp.157-161.

Gleditsch N. P. (2001): Environmental Change: Security and Conflict. In: C. A. Crocker(ed). Turblentpeace: The challenge of managing international Conflict, Washington: U.S. Institute of peace, pp.53-55.

Homer-Dixon (1994): Environmental Scarcities and violent conflict: Evidence from cases. International Security.19 (1):5-40.

Marvin S. Soroos: Approaches to Enhansing Human Security, in Richard A Mathrew, John Bannet and other: p. 178.

Oscar H. Gandy. Jr. et al, (1997): Race and risk factors Affecting the framing of storied about inequality, Discrimination and just plain bad luck. Public opinion quarterly, Vol. 61, No.1., pp.180-182.

Robert M. Entman (1993): Framing Toward Clarification of A Fractured Paradigm, Journal Of Communication, Vol.43, NO.4, 1993, P.52.

Robert M. Entman (2003): Cascading Activation: Contesting the white House's Frame After 11/9 political Communication, Vol. 20, No.4, 2003, P.417. At: http://www.tandfonline.com/doi/abs/10.1080/10584600390 244176\#.Ue471KyModU.

S. N. Soroka (2002): Isuue Attributes and agenda setting by media, the public, and policy makers in Canada. International Journal of public opinion research, Vol.14, NO.3 


$$
\text { معهد الدراسات والبحوث البيئية - جامعة عبن شمس البيئة }
$$

Simon Dalby: Climate Change: New Dimensions of Environmental Security. Pp. 34-43, Published online: 27 June 2013, The RUSI Journal, Volume 158, 2013-issue 3

Tan Kard, J. W. (2001): The Empirical Approach to the Study of Media Framing in S. D. Reese, O. H. Gandy @ A. E. Grant (Eds), Framing Publicize (pp. 95). Mahwah , N. J: Lawernce Erlbaum, 2001.

\title{
TREATMENT OF ENVIRONMENTAL SECURITY DIMENSIONS IN SOME NATIONAL AND INTERNATIONAL NEWS WEBSITES
} (A COMPARATIVE STUDY)

Yousif M. Yousif (1); Moheb M. Kamel ${ }^{(2)}$ and Enas M. Hamed ${ }^{(3)}$

1) Canadian International College 2) Institute of Environmental Studies \& Research, Ain Shams Univerity 3) Faculty of High Studies for Childhood, Ain Shams University

\begin{abstract}
This study drives at identifying the nature of the news websites' treatment of the environmental security dimensions; monitoring as well, the topics of environmental security that the study has focused on. The study exposes the persuasive styles used for environmental security and their journalistic sources; identifying in addition to the different journalistic forms used by the study's examined sites such as eminence elements, support, and the interactive services accompanying the newsletter subjects and materials, standing as well on the agreement and disagreement aspects between the national and the international news websites.
\end{abstract}

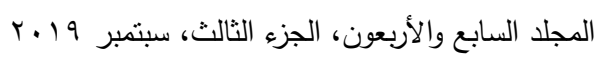


This study belongs to the descriptive (qualitative) studies in which two methods are used: the survey studies method through which the content analysis approach is used and the comparative method through which the methodological comparative approach is used. The researcher also uses "the newsletter frames theory". Data are collected through using the content analysis form. The researcher has used the study sample from news websites as follows: El-Youm El-Sabeih - Sada ElBalad news website and they represent the national local news sites; added to that the Guardian News website and the CNN News Site representing the global news sites. Concerning the time duration of the study, the study is applied using the industrial-week sampling style for about (6 months) starting from $1 / 7 / 2018$ to $31 / 12 / 2018$. The material of the content analysis has included all the topics concerning the dimensions of the various environmental security in the news websites.

The study comes to several results as follows: There are significant statistically differences between national and the international news websites regarding the treatment of the water security, the food security, the biodiversity security, and the biological security. There are no significant statistically differences between national and the international news websites regarding the treatment of the nuclear security and the climate security. 